Ia

Révolution

française

\section{La Révolution française}

Cahiers de l'Institut d'histoire de la Révolution française

$21 \mid 2021$

Les Archives parlementaires entre papier et toile : exploitation d'une source [numéro spécial]

Un coup d'estat républicain : la Journée du 31 mai-2 juin 1793 et la réécriture des procèsverbaux de la Convention

Anne Simonin

(2) OpenEdition

Journals

Édition électronique

URL : https://journals.openedition.org/Irf/5493

DOI : $10.4000 /$ Irf.5493

ISSN : 2105-2557

Éditeur

IHMC - Institut d'histoire moderne et contemporaine (UMR 8066)

Référence électronique

Anne Simonin, « Un coup d'estat républicain : la Journée du 31 mai-2 juin 1793 et la réécriture des procès-verbaux de la Convention », La Révolution française [En ligne], 21 | 2021, mis en ligne le 25 octobre 2021, consulté le 03 novembre 2021. URL : http://journals.openedition.org//rf/5493 ; DOI : https://doi.org/10.4000//rf.5493

Ce document a été généré automatiquement le 3 novembre 2021

(c) La Révolution française 


\title{
Un coup d'estat républicain : la Journée du 31 mai-2 juin 1793 et la réécriture des procès-verbaux de la Convention
}

\author{
Anne Simonin
}

1 La Journée est une unité de temps propre à la Révolution, inspirée à Michelet par SaintSimon $^{1}$. La Journée, explique Michel Vovelle, commence par une sanction et se clôt par un aboutissement ${ }^{2}$. Il s'agit d'une brève séquence temporelle structurée par les événements qui s'y déroulent et non par l'écoulement des heures.

2 La Journée du 31 mai-2 juin 1793 (qui commence en réalité un peu plus tôt, le 27 mai), «sanctionne» la commission extraordinaire dite des Douze, instaurée le 18 mai précédent, sur proposition de Barère, pour enquêter sur les projets de complot dont Paris bruit ${ }^{3}$. Cette commission, où les députés qualifiés de Girondins sont majoritaires ${ }^{4}$, provoque des arrestations : le 24 mai, celle de Hébert, le substitut du procureur de la Commune de Paris et le rédacteur du célèbre Père Duchesne et, dans la nuit du 27 mai, celle du président de la section de la Cité, Dobsen, et de son secrétaire. Cassée une première fois le 27 mai (d'où l'inclusion de ce jour dans la Journée, puisqu'il s'agit bien là d'une sanction), la commission des Douze est rétablie dès le lendemain. Elle est toujours en activité lorsque commence l'insurrection parisienne proprement dite, le 31 mai.

3 La Journée se clôt par la mise en arrestation, le 2 juin 1793, de vingt-neuf députés Girondins et de deux ministres en exercice, Clavière et Lebrun. « Les contemporains ont donné à l'événement le nom de "Révolution du 31 mai" ", écrit Georges Pariset, «l'expression est doublement inexacte, et mieux vaudrait dire: "coup d'état du 2 juin" $»^{5}$.

4 La qualification de coup d'état concernant la Journée du 31 mai-2 juin apparait, dès 1869, sous la plume de l'historien conservateur Mortimer-Ternaux, auteur d'un livre incontournable, ne serait-ce que par les pièces d'archives qu'il contient ${ }^{6}$. Un ouvrage 
publié en 2014 par un journaliste espagnol, Pedro J. Ramirez, interprète, lui aussi, le 31 mai- 2 juin comme un coup d'état en intitulant les près de mille pages qu'il consacre à l'événement: Le Coup d'état. Robespierre, Danton et Marat contre le parlement élu au suffrage universel masculin ${ }^{7}$. Le 31 mai, écrit-il, « une fripouille et un illuminé marchent en tête du petit groupe des sans-culottes " qui s'apprête à soulever Paris contre la Convention. "La fripouille », c'est Guzman (ou Gusman) ; "l'illuminé », Varlet, deux figures de sans-culottes radicaux, dit aussi Enragés, qui vont jouer un rôle clef au Comité de l'Évêché (l'instance qui rassemble les représentants des sections parisiennes insurgées), puis au sein du Conseil général révolutionnaire de la Commune (qui fera figure d'autorité concurrente de la Convention). L'outrance du vocabulaire l'atteste: qualifier le 31 mai-2 juin de coup d'état n'est pas politiquement neutre. Deux ouvrages sur la Journée du 31 mai-2 juin, ceux de Moris Slavin ${ }^{8}$ et de Patrick Lagoueyte ${ }^{9}$, plus indécis sur la nature de l'événement, ouvrent des perspectives autrement fécondes. L'événement fondamental dans l'histoire de la République démocratique qu'est la Journée du 31 mai-2 juin, on l'interrogera ici en l'inscrivant dans une perspective juridique trop négligée et en mobilisant des sources archivistiques délaissées par les historiens : les procès-verbaux réécrits de la Convention.

5 Le 31 mai-2 juin ne met pas seulement aux prises deux factions, la Montagne et la Gironde, mais, tout aussi fondamentalement, deux conceptions du droit révolutionnaire. «Les notions de loi et de législateur ont varié et évolué au cours de l'histoire constitutionnelle ", écrit Carl Schmitt, "mais toujours la loi du légiste est restée fondamentalement différente du droit au sens où l'entendent d'autres types de gardiens du droit ${ }^{10}$ ». "Jusqu'à nos jours ", poursuit Carl Schmitt, «le jugement historique, politique et moral à porter sur l'action du légiste français a suscité d'âpres controverses et des prises de position qui n'ont rien perdu de leur actualité [...]. Dans la vision de l'histoire du républicain démocrate, le légiste français reste le grand pionnier révolutionnaire, [...] de l'égalité civique, des idéaux républicains ${ }^{11}{ }^{11}$.

Représentants du peuple, les Girondins considèrent qu'ils incarnent la souveraineté nationale et expriment la volonté générale dans des lois qui doivent être respectées à la lettre, quelles que soient les rigueurs de la loi et quelles que soient les circonstances. Les Girondins sont des "gardiens du droit». Les Montagnards pensent, eux, que la souveraineté appartient au peuple, qui ne l'exerce pas lui-même, mais par l'intermédiaire de ses représentants. Pour paraphraser Michel Troper, un Girondin exprime la volonté générale parce qu'il est représentant; un Montagnard est représentant parce qu'il participe à l'expression de la volonté générale ${ }^{12} . \mathrm{Si}$, dans certaines circonstances et sous certaines conditions, le peuple exprime son insatisfaction, il exerce sa souveraineté et exprime la volonté générale qu'il revient au législateur de traduire en loi. Les Montagnards sont des "légistes ». "Citoyens, le mouvement qui s'est fait à Paris le 31 mai n'était pas indigne du regard du législateur révolutionnaire » résume le Montagnard Barère à la tribune de la Convention, le 6 juin $1793^{13}$. Privée de ce rapport au droit, qui fonde des positions politiques difficilement conciliables (mais pas irréconciliables grâce à Condorcet $^{14}$, on le verra), la Journée du 31 mai-2 juin peut être réduite à un affrontement d'individus mus par des haines inexpiables et à un coup de force, à un coup d'état 医 la remise en cause illégale de l'ordre juridique se concluant par la mise en arrestation des vingt-neuf députés Girondins, le 2 juin $1793^{15}$. 

vingt-neuf députés Girondins. Avant de se séparer, à 22 heures, la Convention décrète que : «Dès lundi de la semaine suivante [à partir du 10 juin donc] elle ne s'occupera constamment tous les jours, depuis midi jusqu'à six heures, que de la Constitution jusqu'à son achèvement ${ }^{16}{ }^{\prime}$. Inclure, dans le récit et la compréhension du 31 mai-2 juin, cette fin-là, insiste sur le fait que la Journée a aussi un horizon constitutionnel et une ambition: la fondation d'un ordre public républicain démocratique, faisant droit à l'exercice de la souveraineté par le peuple.

8 Le 31 mai-2 juin un droit, le droit d'insurrection ou de résistance à l'oppression, est né en tant que droit positif: il ne s'agit plus d'un droit naturel, contrairement à ce qu'affirment ses ardents défenseurs ${ }^{17}$; il ne s'agit pas non plus d'un droit politique, ajuridique, contrairement à ce qu'écrit la doctrine ${ }^{18}$. C'est lors de cette Journée que le peuple de Paris insurgé a réussi à négocier avec le législateur révolutionnaire l'application d'un droit énoncé, pour la première fois ${ }^{19}$, dans la Déclaration des Droits de l'Homme et du Citoyen de 1789 sous la forme d'un droit naturel (art. $2^{20}$ ). Ce droit naturel, la Déclaration des droits de l'homme en société (art. 1), adoptée le 29 mai 1793, œuvre de Condorcet, le transforme en droit positif ${ }^{21}$. Transformation validée par Robespierre qui, dans la Déclaration des droits appelée à succéder à celle de Condorcet, extrait le droit d'insurrection de la liste des «droits naturels et imprescriptibles» de l'homme où l'avait placé la Déclaration de 1789 (art. 2) ${ }^{22}$ pour en faire la « conséquence des autres droits de l'homme» (art. 33) et le définir comme «le plus sacré des droits et le plus indispensable des devoirs » (art. 35). Droit de nature mixte, naturel par son caractère sacré, positif par sa dimension de devoir, le droit d'insurrection est appelé à devenir la clef de voûte de l'ordre public républicain démocratique institué par la Déclaration des droits de l'Homme et du Citoyen, préambule de la Constitution de l'an I (24 juin 1793).

La Journée du 31 mai-2 juin débouche donc sur la conquête d'un droit fondamental nouveau du citoyen et non sur les marches de l'échafaud qui conduiront, cinq mois plus tard, les Girondins à la mort, selon la lecture déterministe qui trop souvent prévaut dans l'historiographie de langue française de la Révolution d'après William Doyle ${ }^{23}$. Dissociée de l'échafaud, pensée en tenant compte de la dimension imprévisible de l'événement et de l'agenda juridico-politique qui lui est propre, la Journée du 31 mai-2 juin n'est pas un coup d'état mais un «coup d'estat » voué à demeurer sans équivalent dans les annales de la République.

«Coup d'état » : rares sont les locutions qui ont, à ce point, changé de sens au cours des siècles. Quand parait, en 1631, l'opuscule de Jean Sirmond, Le coup d'Estat de Louis XIII, à propos de la Journée des Dupes, Louis XIII agit, aux yeux de son auteur, «pour le bien de l'État $»^{24}$. Huit ans plus tard, Gabriel Naudé reprend l'expression pour la théoriser, dans ses Considérations politiques sur les coups d'Estat, publiées en 1639. Le " coup d'estat " est toujours « une mesure extraordinaire contre le droit commun dictée au souverain par le souci du bien public ${ }^{25}$ ». C'est au XIX $x^{e}$ siècle, selon Maurice Agulhon, que le coup d'état, perdant son « $\mathrm{s}$ », est devenu " une expression absolument péjorative », un coup de force perpétré contre l'état de droit et les droits fondamentaux des individus ${ }^{26}$.

11 Pour comprendre ce qui se joue lors de la Journée du 31 mai-2 juin, il convient de s'intéresser au discours qui légalise et légitime le «coup d'estat » au moins autant qu'à l'action qui le produit. Une source négligée devient alors fondamentale: le procèsverbal réécrit des séances de la Convention. Parce qu'il est «à lui seul la preuve légale

La Révolution française, 21 | 2021 
de la vérité de son contenu » dira Merlin de Douai ${ }^{27}$, le procès-verbal donne accès à une compréhension autre de l'événement.

Pourquoi la Convention a-t-elle décidé de réécrire les procès-verbaux de ses séances des 27 mai, 31 mai et 2 juin 1793 ? Doit-on interpréter la réécriture comme une opération de propagande ayant pour but de magnifier la victoire de la Montagne sur la Gironde? Ou doit-on y voir une opération d'une toute autre ampleur, une narration itérative de l'événement liée à l'émergence d'un nouvel univers normatif ${ }^{28}$, celui d'une République à la fois représentative et démocratique où le Peuple ${ }^{29}$ exerce une souveraineté immédiate grâce à un droit nouveau, le droit d'insurrection?

\section{Robespierre, collaborateur de Condorcet ${ }^{30}$}

Si un coup d'état est selon Hans Kelsen " toute modification de la constitution ou tout changement ou substitution de constitution qui ne sont pas légitimes, c'est-à-dire qui ne sont pas opérés conformément aux dispositions de la Constitution en vigueur ${ }^{31}$ ", comment le 31 mai-2 juin pourrait-il être un coup d'état puisque la France n'a alors pas de constitution, le projet présenté par le girondin Condorcet et lu à l'assemblée les 15 et 16 février 1793 n'ayant pas été adopté ? En l'absence de constitution, la République n'est toutefois pas dans une situation anomique. La, ou plutôt les, Déclaration des Droits de l'Homme, celle de 1789 et celle alors en discussion de 1793, tiennent lieu de norme juridique supérieure.

Le 27 mai, la députation de la section de la Cité est admise à la barre de la Convention et dénonce en ces termes l'arrestation de son président, Dobsen, et de son secrétaire, sur ordre de la Commission des Douze : « Les citoyens révoltés de cet ordre, qui surpasse les lettres de cachet, [...] nous ont députés vers vous pour vous instruire de cette violation des droits de l'homme et du citoyen $^{32}$ " [souligné par moi].

Henri Wallon livre ce détail supplémentaire : la section de la Cité porte « un écriteau où se lisaient ces mots: "Droits de l'homme violés", surmonté d'un bonnet couvert d'un crêpe noir ${ }^{33}$ ». Un peu plus tard, dans le débat houleux qui s'engage, Chasles dit : « La résistance à l'oppression est un des droits de l'homme. Les droits de l'homme sont avant la Convention ${ }^{34}$.»

Dit autrement: la Déclaration des Droits formule des principes qui s'imposent au législateur constituant et au législateur ordinaire (la Convention est les deux à la fois) ${ }^{35}$. Et la Déclaration des Droits de 1789 a reconnu la « résistance à l'oppression » comme « droit naturel et imprescriptible » de l'homme (art. 2).

17 La Déclaration des Droits girondine, en grande partie œuvre de Condorcet, dont la Convention a commencé la discussion en avril 1793, va accroître la puissance de ce droit, en le transformant, sur proposition de l'avocat Vergniaud, autre membre influent de la Gironde, en un droit positif: "Je demande qu'abandonnant la distinction de naturel et de social, la Convention adopte cette rédaction: "Les droits de l'homme en société sont l'égalité, la liberté, la sûreté, la propriété et la résistance à l'oppression". Cette rédaction est adoptée à l'unanimité ${ }^{36} »$.

18 Cette formulation devient l'article 1 de la Déclaration des Droits, dite Girondine, adoptée par la Convention, le 29 mai 1793. La rupture majeure que cette Déclaration introduit avec la Déclaration de 1789 est insuffisamment soulignée. En remplaçant le droit naturel flou de 1789 (la résistance à l'oppression) par un droit civil, un droit 
positif de l'homme en société, les Girondins inventent et codifient en 1793, à la veille du 31 mai-2 juin, le droit d'insurrection. Ce droit ne peut toutefois s'exercer que selon des moyens légaux, inscrits dans la Constitution.

Si le projet de Déclaration girondine des Droits définit précisément ce qu'est une situation d'oppression; et si le projet de Constitution girondine consacre un titre entier à la "Censure du peuple ${ }^{37}$ » ainsi qu' à l'exercice du droit d'insurrection, Robespierre reproche aux Girondins un usage beaucoup trop restrictif, pour ne pas dire irréaliste, de ce droit et leur oppose un refus cinglant : il « estime qu'il est parfaitement ridicule de définir les cas d'oppression ${ }^{38}[. .$.$] » et qu' « assujettir à des formes légales la résistance$ à l'oppression est le dernier raffinement de la tyrannie ${ }^{39}$ ».

Si l'opposition de Robespierre à Condorcet est toujours soulignée, on remarque moins, en revanche, un silence qui vaut approbation. Si les «droits naturels et imprescriptibles de l'homme" réapparaissent dans la Déclaration des Droits montagnarde adoptée le 24 juin $1793^{40}$, la résistance à l'oppression n'en fait plus partie : seules l'égalité, la liberté, la sûreté et la propriété sont désormais «droits naturels et imprescriptibles » précise l'article 2. La transformation de la résistance à l'oppression en droit positif d'insurrection proposée par les Girondins est, de fait, ratifiée par les Montagnards. Et réciproquement. Les rapports exécrables entre les individus parasitent sans aucun doute, mais ne paralysent pas l'échange d'idées entre des hommes qui sont tous des républicains convaincus. Quand Condorcet admet la nécessité du droit d'insurrection et le constitutionnalise, il modifie, en réalité, sa conception de la souveraineté générale. Tout en attribuant la jouissance exclusive de la souveraineté aux représentants, il admet désormais le peuple à l'exercice de la souveraineté.

21 Si les représentants du peuple élus jouissent de mandats illimités et incarnent seuls la souveraineté nationale, Condorcet admet, en février 1793, les citoyens à l'exercice de la souveraineté. Il leur reconnaît un droit d'intervention dans le processus de révision continue des lois, à quoi se résume pour lui le droit d'insurrection. Ainsi que l'analyse de façon lumineuse Lucien Jaume: "Représentation et "exercice immédiat" [l'expression est de Condorcet] de la souveraineté par les citoyens: il s'agit véritablement de la première tentative pour penser et surmonter l'aporie rencontrée depuis 1789. Deux termes qui ont paru jusqu'à présent incompatibles [...] vont être rendus complémentaires dans leurs objets et interdépendants dans leur fonctionnement ${ }^{41} »$.

Mais comment articuler les rapports entre la souveraineté nationale (les représentants du peuple) et la souveraineté populaire (le droit d'insurrection) ? En transformant le droit naturel de résistance à l'oppression en droit positif d'insurrection et en détaillant l'exercice de ce droit dans la constitution, répondent les Girondins ; en faisant du droit d'insurrection un droit fondamental du citoyen énoncé dans la seule Déclaration des droits, donc régulé de façon plus souple, répondent les Montagnards. S'il n'a pas vocation à être constitutionnalisé, sous risque d'être paralysé, le droit d'insurrection est toutefois assujetti à des contraintes juridiques qui conditionnent sa légitime application sous le régime juridique des Déclarations des Droits girondine et montagnarde de $1793^{42}$. Dégagées pendant la première mise à l'épreuve de ce droit nouveau, lors de la Journée du 31 mai- 2 juin, ces contraintes se trouvent exprimées dans la réécriture des procès-verbaux des séances de la Convention et reçoivent, du fait de leur énonciation au procès-verbal, valeur légale. 
Si la Journée du 31 mai-2 juin marque indubitablement la défaite des députés girondins, elle marque aussi cependant, et c'est là son paradoxe, la victoire des idées de la Gironde: la République sera représentative. C'est après le 31 mai-2 juin que le législateur montagnard renonce définitivement au mandat impératif, dit aussi " explicatif », réclamé par l'aile gauche des insurgés ${ }^{43}$. " Ainsi la constitution de 1793, prétendument fondée sur le principe de la souveraineté populaire, [prohibe] expressément le mandat impératif " écrit Michel Troper ${ }^{44}$. Mais si les positions en faveur de la prééminence et de l'autonomie de la souveraineté nationale défendues par la Gironde l'emportent, c'est aux Montagnards que le peuple doit la grammaire de ce droit nouveau qu'est le droit d'insurrection. La République ne sera pas que représentative. Elle sera également démocratique. La République représentative et démocratique à laquelle aspire la Journée du 31 mai-2 juin doit, en réalité, autant à la Gironde qu'à la Montagne.

Cette vérité, cachée sous l'affrontement sans merci que viennent de se livrer les deux factions au sein de la Convention, masquée par la «victoire» de la Montagne sur la Gironde, occultée par une histoire politique dissociée de l'histoire du droit, seule l'étude de la réécriture des procès-verbaux des séances de la Convention permet de la formuler et de la comprendre.

\section{Une opération inédite : la réécriture du procès-verbal}

Dans l'histoire de la Convention nationale, avant la Journée du 31 mai-2 juin, il n'y a pas d'exemple de réécriture des procès-verbaux des séances de l'assemblée ${ }^{45}$. Il n'y a pas de suite non plus. À l'exception de la Journée du 9 thermidor (27 juillet 1794), qui voit la chute de Robespierre et des Robespierristes, la Convention ne réécrira plus jamais ses procès-verbaux. Pourquoi la Journée du 31 mai- 2 juin fut-elle l'objet d'un traitement si exceptionnel et si singulier de la part du législateur?

La réécriture décidée par la Convention rythme la Journée du 31 mai-2 juin d'une drôle de manière : elle inclut dans son périmètre une date qui ne lui appartient pas (la séance du 27 mai) ; elle privilégie les séances du 31 mai et 2 juin, comme s'il ne s'était rien passé les 30 mai et $1^{\mathrm{er}}$ juin $^{46}$. Arythmique, la réécriture est aussi chaotique. Entreprise le 19 juin, elle est d'abord partielle (séance du 27 mai), puis intégrale (séances du 31 mai et 2 juin). Validée par la Convention le 10 septembre 1793, soit plus de trois mois après l'événement, elle est rendue publique dans un contexte radicalement modifié, alors que les Montagnards Jean Bon-Saint-André, Billaud-Varenne et Robespierre se succèdent à la présidence de l'assemblée. La réécriture, quand on la commente 医 et seuls les auteurs du XIX ${ }^{e}$ siècle le feront 㡠, est, de ce fait, considérée comme un acte partisan auquel il convient de ne pas accorder foi.

27 Le député Girondin Durand-Maillane (1729-1814), canoniste réputé, occupant, le 2 juin, la position de secrétaire de la Convention et chargé, à ce titre, de la rédaction du procès-verbal de la séance, écrit dans ses Mémoires (1825) :

Dans la séance du 29 [mai 1793] et celles qui suivirent, les Montagnards, irrités de leur défaite, exigèrent qu'on la déguisât dans le procès-verbal : ce qui fut également ordonné pour le procès-verbal de la séance du 2 juin que j'avais rédigé moi-même comme secrétaire. Il est bon qu'on le sache afin que l'on connaisse mieux avec quelle droiture et quelle probité se conduisaient les Montagnards dans la 
Convention, et qu'on ajoute plus de foi à nos récits, à ceux des témoins oculaires et désintéressés qu'à leurs procès-verbaux ${ }^{47}$. Montagnards sont allés jusqu'à détruire toute trace des procès-verbaux d'origine :

Les procès-verbaux officiels des séances des 27,28 et 31 mai avaient été rédigés lorsque la Convention était encore maîtresse d'elle-même; mais ils contenaient trop visiblement l'indication des violences exercées sur l'assemblée par les émeutiers du dedans et du dehors pour que les vainqueurs laissent subsister cette preuve irrécusable de leurs méfaits [...]. Lorsque qu'après le meurtre de Marat, ils devinrent tout puissants dans l'Assemblée, ils firent disparaître les trois procèsverbaux dont le texte trop véridique les offusquait et leur en substituèrent d'autres, que les membres du bureau alors en exercice furent appelés à signer [...]. C'est ainsi que Jean Bon-Saint-André et Robespierre, qui présidaient l'Assemblée [...], ont apposé leur signature au bas de ce faux audacieux [... $]^{48}$.

On passe sur les inexactitudes de date. L'attaque est rude : les procès-verbaux réécrits de la Convention seraient des faux " en écriture authentique et publique " (un crime que le Code pénal de 1791 alors toujours en vigueur punit de huit années de fers).

C'est à l'homme politique et historien, lui aussi conservateur, mais républicain, Henri Wallon, qu'en 1886, les procès-verbaux primitifs doivent de refaire surface. Il exhume cette source, la localise dans la série C (cartons 253 et 256) des Archives nationales et voit là « une rédaction bien officielle, bien mûrement revue et corrigée : trop officielle, trop corrigée sans doute; on ne peut plus la prendre qu'avec défiance et l'on a des raisons de croire que tout n'y est pas dit $^{49}$ ».

31 En 1897, donc dix ans après la publication du livre d'Henri Wallon, les rédacteurs des Archives parlementaires lancent la série des volumes concernant la Convention. Alors que le procès-verbal est revendiqué par eux comme la colonne vertébrale de la reconstitution des séances de l'assemblée ${ }^{50}$, ils ignorent le procès-verbal en partie double de la Journée du 31 mai-2 juin au profit d'une compilation d'extraits des journaux de l'époque ${ }^{51}$. Le Moniteur semble avoir été, bien davantage que les procèsverbaux de la Convention, la "matrice » de la Journée du 31 mai-2 juin aux Archives parlementaires. Ce choix méthodologique n'est pas neutre.

$\mathrm{Vu}$ le caractère incontournable des Archives parlementaires pour qui s'intéresse à l'histoire politique de la Révolution, cet effacement de la réécriture des procès-verbaux de la Journée du 31 mai- 2 juin obscurcit la compréhension des enjeux juridiques au profit des affrontements rhétoriques qui mettent aux prises Girondins et Montagnards dans cette enceinte agonistique qu'est devenue la Convention : «Après le jugement et le châtiment du dernier roi, les débats de la Convention n'étaient plus des discussions sur les principes ; c'était des querelles sur les personnes » note, désabusé, Garat dans ses Mémoires ${ }^{52}$.

La réécriture marque toutefois une rupture majeure dans l'histoire du procès-verbal des assemblées révolutionnaires, littérature juridique dans laquelle on eût été jusque-là en peine de trouver la moindre trace de passion ou d'émotion.

Le procès-verbal est une initiative de l'assemblée du Tiers-État lors des États-Généraux, le 29 mai 1789. « À partir du 12 juin 1789 ", écrit Guffrey, « il se publia un procès-verbal imprimé des délibérations [...] qui, à dater du 17 juin, devint le procès-verbal de l'Assemblée nationale. Chaque séance, formant un fascicule séparé, porte la signature du président et des secrétaires ${ }^{53}$ ». Ces signatures multiples ont un but: «que le contenu [du procès-verbal] ne puisse être révoqué en doute ${ }^{54} »$. 

renvoyé au Comité des Décrets pour en revoir la rédaction ». Cette dernière proposition est adoptée ${ }^{62}$. Ce faisant, la Convention invente une procédure qui n'a aucune existence réglementaire: jamais il n'a été jusque-là question de dessaisir le secrétariat de la Convention de la révision du procès-verbal au profit du Comité des Décrets. Ce dernier inflige un blâme modéré au girondin Pénières, puisque seule une partie du procèsverbal du 27 mai est rectifiée par lui. Cette version corrigée du procès-verbal de la séance du 27 mai est adoptée par la Convention le 20 juillet suivant ${ }^{63}$. réécriture demandée par le Montagnard Chabot: 
[...] les secrétaires [auraient dû] lire les procès-verbaux des séances du 31 mai et du 2 juin dont, j'ose le dire, dépend la liberté publique. Eh bien! Ils ne l'ont pas fait; car le côté gauche, qui a terrassé les conspirateurs, n'aurait pas laissé passer les impostures dont les procès-verbaux sont souillés. Il faudrait vous les lire en entier pour vous prouver qu'ils ne sont qu'un tissu de mensonges et de calomnies. En voici quelques passages : "Divers députés ont parlé contre cette continuité d'oppression". De manière qu'on peint la Convention nationale comme dans l'oppression, le jour qu'elle a sauvé la patrie en se purgeant des conspirateurs. "Isnard, compris dans cette liste, a demandé la parole et après avoir exposé avec énergie ses sentiments patriotiques, a fini, dans son dévouement entier pour la patrie, par offrir lui-même sa suspension, demandée comme un sacrifice nécessaire à la paix publique. Fauchet a exprimé les mêmes sentiments qui ont été agréés par l'assemblée. Barbaroux, Lanthenas et Dussaulx ont aussi parlé le langage d'hommes dévoués également au bien de la patrie, après quoi on est passé à la délibération et le décret a été rendu à travers bien des réclamations. Plusieurs membres sont venus signer au bureau la déclaration qu'ils n'avaient pris aucune part à ce décret". Sans doute Fauchet, Guadet et leurs complices rédigeaient de semblables procès-verbaux et les répandaient dans les départements. Je n'en suis pas surpris ; mais qu'en votre nom ils aient été portés à l'impression, sans vous avoir été lus, voilà ce qui m'étonne. S'ils avaient été lus le 5 ou 6 juin, je crois que le côté droit aurait permis aux patriotes d'y faire les changements qu'exigeait la vérité mais j'atteste qu'on n'en a point fait lecture. Je demande que la Convention s'inscrive en faux contre ces procès-verbaux rédigés par les ennemis de la chose publique, qu'elle déclare qu'elle n'a jamais approuvé cette rédaction mensongère, et qu'elle ordonne une rédaction nouvelle du procès-verbal de ces séances qui ont sauvé la liberté [...]. Je demande le rapport du décret qui ordonne la distribution des procès-verbaux que $\mathrm{j}$ 'ai dénoncés ${ }^{64}[\ldots]$.

41 La Convention ne suit pas aveuglément Chabot: elle applique, en août 1793, la procédure inventée par elle le 19 juin précédent ${ }^{65}$ et sollicite le Comité des Décrets pour prendre connaissance des minutes, de la version manuscrite originale, du procès-verbal incriminé (décret du 12 août). Quatre jours plus tard, "après avoir entendu le rapporteur du Comité des Décrets ", la Convention décrète « que les procès-verbaux des séances des 31 mai-2 juin derniers seront révisés et rédigés de nouveau par le comité des décrets, concurremment avec les secrétaires qui en ont d'abord fait la minute » [souligné par moi] (décret du 16 août 1793) ${ }^{66}$. Preuve que la réécriture est tout autre chose qu'un règlement de compte politique, la Convention exige que les rédacteurs Girondins des procès-verbaux primitifs y soient associés. Si tel a été le cas, le girondin Durand-Maillane n'en a visiblement conservé aucun souvenir (voir supra).

Le procès-verbal primitif de la séance du 2 juin, rédigé par lui, est, en réalité, gravement fautif au vu des règles d'écriture de n'importe quel procès-verbal (rupture de l'anonymat, description des échanges houleux de la séance, mention des sentiments des députés...). " J'ai rendu compte de la généralité des faits de manière que l'on puisse voir dans quel état la Convention a délibéré » dira Durand-Maillane à l'assemblée le 4 juin, quand il donne lecture de son procès-verbal. L'abbé Grégoire est pour; les Montagnards (Legendre, Thuriot) sont contre : «La Convention passe à l'ordre du jour, et après quelques changements dans les expressions, adopte la rédaction présentée par Durand-Maillane " [souligné par moi] ${ }^{67}$. C'est cette version amendée que Baudouin publie dans sa collection du Procès-verbal de la Convention nationale ${ }^{68}$. La séance du 2 juin est ainsi la seule à avoir fait l'objet de deux procès-verbaux adoptés et publiés, le primitif (corrigé) et le réécrit. Ce qui était acceptable le 4 juin, ne l'est plus le 12 août alors qu'une nouvelle Déclaration des Droits et la Constitution ont été adoptés et que 
certains Girondins désormais traitres à la patrie (cf. infra). Pourquoi ? Si le procèsverbal n'est pas réécrit, la Journée du 31 mai-2 juin est un coup d'état ou un coup de force perpétré par la Montagne contre la Gironde; si le procès-verbal est réécrit, la Journée du 31 mai-2 juin est un coup d'estat en faveur de la République démocratique. Dit autrement, la République démocratique n'a pas seulement besoin d'une Déclaration et d'une Constitution: elle a désormais l'une et l'autre. Elle a besoin d'un récit fondateur. L'ambition de ce récit n'est pas d'effacer ce qui s'est passé (les deux, voire les trois, versions des procès-verbaux subsistent à l'état manuscrit ou publié). Modifier la narration officielle de l'événement vise à mettre l'accent non plus sur les déchirements de la Convention mais sur l'avènement du peuple républicain.

\begin{tabular}{|c|c|}
\hline $\begin{array}{l}\text { Procès-verbal primitif (corrigé) de la séance du } \\
2 \text { juin } 1793 \text { dénoncé par Chabot dont un extrait est } \\
\text { lu par lui à la tribune de la Convention, le } 12 \text { août } \\
1793 \\
\text { NdA : Est ici donnée la version intégrale } \\
\text { imprimée par Baudouin, en indiquant en gras } \\
\text { les variantes et les passages omis par Chabot }{ }^{69}\end{array}$ & $\begin{array}{l}\text { Procès-verbal de la séance du } 2 \text { juin réécrit, rédigé par } \\
\text { le Comité des Décrets en vertu du décret du } 16 \text { août } \\
1793, \text { lu et adopté par la Convention le } 10 \text { septembre } \\
\text { suivant, également imprimé par Baudouin }{ }^{70} \text {. }\end{array}$ \\
\hline $\begin{array}{l}\text { Isnard, compris dans cette liste, a demandé la } \\
\text { parole et après avoir exposé avec énergie ses } \\
\text { sentiments patriotiques, a fini, dans son } \\
\text { dévouement entier pour la Patrie, par offrir } \\
\text { lui-même sa suspension, demandée comme un } \\
\text { sacrifice nécessaire à la paix et au bien de la } \\
\text { chose publique. } \\
\text { Fauchet a exprimé les mêmes sentiments qui } \\
\text { ont été fort agréés par l'Assemblée. }\end{array}$ & $\begin{array}{l}\text { La discussion sur les Membres dénoncés est } \\
\text { reprise et se fixe sur leur mise en état } \\
\text { d'arrestation. Plusieurs Membres obtiennent la } \\
\text { parole pour et contre. La Commission des Douze } \\
\text { est entendue: on demande la clôture de la } \\
\text { discussion, la discussion est fermée. } \\
\text { On donne lecture de la liste des Membres } \\
\text { dénoncés par le Département, la Commune et les } \\
\text { Sections de Paris. } \\
\text { On propose plusieurs amendemens. }\end{array}$ \\
\hline $\begin{array}{l}\text { Barbaroux, Lanthenas et Dussaulx ont aussi } \\
\text { parlé [variante : "ont parlé aussi dans ce } \\
\text { qui les concernait] le langage d'hommes } \\
\text { dévoués également au bien de la Patrie, après } \\
\text { quoi on est passé à la délibération et le Décret } \\
\text { a été rendu à travers bien des réclamations et } \\
\text { en exceptant, sur la motion d'un Membre, de la } \\
\text { liste des députés dénoncés Isnard et Fauchet à } \\
\text { cause de la suspension qu'ils avaient offerte } \\
\text { d'eux-mêmes, mais en leur défendant la sortie } \\
\text { de Paris. On a demandé la même exception } \\
\text { sous la même défense pour ceux du Comité des } \\
\text { Douze qui ont été d'avis contraire à ses } \\
\text { mandats d'arrêt. }\end{array}$ & $\begin{array}{l}\text { On demande que les citoyens Dussaulx, Lanthenas } \\
\text { et Ducos, compris dans la liste, en soient retirés. } \\
\text { On demande une exception en faveur des citoyens } \\
\text { Boyer-Fonfrède et St. Martin, Membres de la } \\
\text { Commission des Douze, lesquels se sont opposés } \\
\text { aux arrestations arbitraires prononcées par cette } \\
\text { Commission. On demande qu'Isnard et Fauchet, } \\
\text { qui se sont volontairement suspendus de leurs } \\
\text { fonctions de Députés, ne soient point mis en état } \\
\text { d'arrestation, mais qu'il leur soit simplement } \\
\text { défendu de sortir de la ville de Paris. On demande } \\
\text { que le Décret qui interviendra contre les } \\
\text { dénoncés, porte qu'ils seront mis en état } \\
\text { d'arrestation chez eux. Tous ces amendemens } \\
\text { sont adoptés. }\end{array}$ \\
\hline $\begin{array}{l}\text { Voici la teneur du Décret }[\mathrm{de} \text { mise en } \\
\text { arrestation à leur domicile des vingt-neuf } \\
\text { députés Girondins et des deux ministres en } \\
\text { exercice] }\end{array}$ & $\begin{array}{l}\text { La Convention nationale rend le Décret suivant } \\
\text { [de mise en arrestation à leur domicile des vingt- } \\
\text { neuf députés Girondins et des deux ministres en } \\
\text { exercice.] }\end{array}$ \\
\hline
\end{tabular}




\begin{tabular}{|c|c|}
\hline $\begin{array}{l}\text { Le Décret a été à peine prononcé, qu'un } \\
\text { grand nombre de Députés sont venus au } \\
\text { Bureau réclamer contre, et ont signé } \\
\text { diverses déclarations pour qu'il conte qu'ils } \\
\text { n'approuvent point ce Décret et qu'ils n'ont } \\
\text { point part à la délibération. }\end{array}$ & Non mentionné \\
\hline $\begin{array}{l}\text { Aussitôt après le Président a reçu une lettre } \\
\text { souscrite par trois signataires, qui se disant } \\
\text { Députés du Peuple entier du Département } \\
\text { de Paris, annoncent à la Convention, que le } \\
\text { Décret qu'elle vient de rendre est le salut de } \\
\text { la République, et ont offert de se constituer } \\
\text { en otages en nombre égal à celui des } \\
\text { Députés mis en état d'arrestation, pour } \\
\text { répondre à la France entière de leur sûreté; } \\
\text { sur quoi } \\
\text { Barbaroux prenant la parole a dit qu'il } \\
\text { n'avait besoin pour otage que de ses } \\
\text { sentimens et de sa conscience, qu'il était } \\
\text { suffisamment rassuré par la sauve-garde du } \\
\text { Peuple français et de la loyauté du Peuple } \\
\text { de Paris. }\end{array}$ & $\begin{array}{l}\text { Le Président lit la lettre suivante: } \\
\text { «Législateur, le peuple de Paris nous députe vers } \\
\text { vous, pour vous dire que le Décret que vous venez } \\
\text { de rendre, est le salut de la République. Nous } \\
\text { venons vous offrir de nous constituer en otage, en } \\
\text { nombre égal à celui des Députés mis en état } \\
\text { d'arrestation, pour répondre à la France entière } \\
\text { de leur sûreté ». } \\
\text { La députation est admise aux honneurs de la } \\
\text { séance. Sur la proposition d'un Membre, la } \\
\text { Convention nationale décrète que cette lettre sera } \\
\text { imprimée et insérée au Bulletin. }\end{array}$ \\
\hline $\begin{array}{l}\text { Sur la motion d'un Membre, qui a observé } \\
\text { que la suspension offerte par Isnard et } \\
\text { Fauchet méritait certains égards, il } \\
\text { demande qu'ils ne fussent pas mis en état } \\
\text { d'arrestation mais qu'il leur fut seulement } \\
\text { interdit de sortir de la ville de Paris, ce qui } \\
\text { a été décrété. }\end{array}$ & [Ce paragraphe est déplacé plus haut] \\
\hline $\begin{array}{l}\text { Par un dernier décret la Convention } \\
\text { nationale a arrêté que pendant tout le cours } \\
\text { de cette semaine, elle s'occuperait des } \\
\text { objets de finances et autres plus } \\
\text { intéressants, mais que dès Lundi de la } \\
\text { semaine suivante, elle ne s'occuperait } \\
\text { constamment, tous les jours, depuis midi } \\
\text { jusqu'à six heures, que de la Constitution } \\
\text { jusqu'à son achèvement. }\end{array}$ & $\begin{array}{l}\text { On demande, qu'à compter de lundi prochain en } \\
\text { huit, la Convention nationale s'occupe de la } \\
\text { Constitution, tous les jours, depuis midi jusqu'à } \\
\text { six heures du soir. Cette proposition est décrétée. }\end{array}$ \\
\hline $\begin{array}{l}\text { Plusieurs membres sont venus signer au } \\
\text { bureau la déclaration qu'ils n'avaient pris } \\
\text { aucune part à ce décret. }\end{array}$ & Non mentionné \\
\hline La séance a été levée à dix heures du soir. & La séance est levée à onze heures. \\
\hline
\end{tabular}
est de droit au procès-verbal : ce dernier ne peut admettre l'expression d'un désaccord 
formel de la minorité vis-à-vis de la loi votée par la Convention. La suppression des réactions des Girondins est de droit au procès-verbal qui ignore les réactions personnelles des députés en séance et ne doit laisser paraître ni la sensibilité politique, ni les émotions des représentants du peuple. On remarque toutefois que la version réécrite contient davantage de noms de députés (sept) que le version primitive (cinq), rompant de fait avec la règle de l'anonymat. Ce ne sont pas les mêmes députés qui sont cités et, surtout, ils ne sont pas cités pour les mêmes raisons. Dans la version primitive, les députés cités expriment leurs "sentiments"; dans la version réécrite, ils ne sont mentionnés que parce que leurs noms figurent sur les «amendements» au projet de décret adopté par la Convention. Voir là une forme de censure est possible mais ne permet pas de comprendre que le procès-verbal est un récit sous des contraintes narratives fortes que respecte la réécriture. La véritable novation introduite par la réécriture réside dans le traitement de la lettre lue à la tribune de la Convention par le président de séance, le Montagnard Mallarmé.

Là où la rédaction primitive ne voit que «trois signataires se disant Députés du Peuple entier du Département de Paris » et énonce le contenu de la lettre au style indirect, dont la réaction du Girondin Barbaroux atteste la vanité (pour ne rien dire de la suffisance), la réécriture entend une « députation » du peuple de Paris, dont la lettre est lue à la tribune de l'assemblée, dans son intégralité, par le président, avec ces précisions omises au procès-verbal primitif : «La députation est admise aux honneurs de la séance »; "la Convention nationale décrète que cette lettre sera imprimée et insérée au Bulletin» - en réalité au Feuilleton de la Convention, où sont imprimés les décrets adoptés journellement par elle et toutes les marques de distinction dont l'assemblée honore les citoyens. La réaction de Barbaroux est omise. Le traitement réservé à la présence du peuple est la grande différence entre le procès-verbal primitif et le procès-verbal réécrit.

Que convient-il d'entendre ici par peuple? Selon Pedro J. Ramirez, moins de $1 \%$ de la population parisienne a participé à la Journée du 31 mai- 2 juin. Il précise toutefois que les pétitionnaires du Faubourg Saint-Antoine viennent à la Convention accompagnés de 8 à 9000 personnes, ce qui représente un habitant sur cinq du Faubourg (qui en compte $46000)^{71}$. D'un point de vue sociologique, le peuple de la Journée du 31 mai-32 juin se réduit soit à une ultra-minorité, soit à un quartier de Paris particulièrement mobilisé.

Trente-trois sections sur quarante-huit envoient des délégués les représenter au Conseil général révolutionnaire de la Commune, l'instance insurrectionnelle fédérative. Tiendrait-on là une majorité plus représentative? «Quand le gouvernement viole les droits du peuple, l'insurrection est, pour le peuple et pour chaque portion du peuple, le plus sacré des droits et le plus indispensable des devoirs" [souligné par moi] dit Robespierre $^{72}$. L'activation légale $d u$ droit d'insurrection ne dépend donc pas du nombre : en la matière, toute « portion » du peuple vaut Peuple (majuscule de rigueur). Mais comment transformer le peuple de Paris insurgé en cette fiction juridique, le Peuple, que le législateur déclare et inscrit dans un texte de loi $^{73}$ (la Déclaration des droits) et que, dans la réalité, les représentants doivent admettre au coexercice de la souveraineté, en accordant satisfaction immédiate à certaines de ses revendications? Une autre séquence, placée en début de séance, permet d'analyser plus finement cette opération du droit à laquelle va se livrer la réécriture. s'étant séparée la veille à minuit, le sort des députés Girondins dénoncés par les 
sections de Paris depuis le 27 mai n'est toujours pas fixé. Les adresses et les pétitions lues à la tribune se multiplient. Les canons de la Garde nationale et des milliers de sansculottes entourent la salle des séances aux Tuileries. Les députés sont prisonniers ou quasiment, devant négocier toute sortie avec les inconnus qui encombrent les couloirs, les femmes qui bloquent les entrées ${ }^{74} . .$. L'atmosphère est extrêmement tendue.

\begin{tabular}{|c|c|}
\hline $\begin{array}{l}\text { Procès-verbal primitif (corrigé) de la } \\
\text { séance du } 2 \text { juin } 1793 \text { imprimé par } \\
\text { Baudouin }^{75}\end{array}$ & Procès-verbal réécrit de la séance du 2 juin imprimé par Baudouin ${ }^{76}$ \\
\hline $\begin{array}{l}\text { «Une Députation se présente au } \\
\text { nom du Conseil Général de la } \\
\text { Commune de Paris, }\end{array}$ & $\begin{array}{l}\text { "Le Président annonce qu'une députation des autorités } \\
\text { révolutionnaires constituées de Paris demande à être admise } \\
\text { à la barre pour présenter à la Convention les dernières } \\
\text { mesures de salut public. } \\
\text { Quelques membres s'opposent à son admission, elle est mise } \\
\text { aux voix et décrétée. } \\
\text { On demande que les pétitionnaires justifient leurs pouvoirs; } \\
\text { ils les déposent sur le bureau, et un secrétaire en donne } \\
\text { lecture. } \\
\text { L'Orateur de la députation obtient la parole et dit: } \\
\text { Délégués du peuple }\end{array}$ \\
\hline $\begin{array}{l}\text { et demande que sur-le-champ on } \\
\text { mette en état d'arrestation les } \\
\text { Membres dénoncés dans la } \\
\text { Convention, et annonce que c'est } \\
\text { pour la dernière fois. }\end{array}$ & $\begin{array}{l}\text { Depuis quatre jours, le peuple de Paris n'a pas quitté les } \\
\text { armes; ses mandataires auxquels il n'a cessé de réclamer ses } \\
\text { droits indignement violés, se rient de son calme et de sa } \\
\text { persévérance. Le flambeau de la liberté pâlit, les colonnes de } \\
\text { l'égalité sont ébranlées, les contre-révolutionnaires lèvent la } \\
\text { tête; qu'ils tremblent ! La foudre gronde et va les pulvériser. } \\
\text { Représentants, les crimes des factieux de la Convention vous } \\
\text { sont connus; nous venons pour la dernière fois vous les } \\
\text { dénoncer. Décrétés (sic), à l'instant, qu'ils sont indignes de la } \\
\text { confiance de la nation; mettez-les en état d'arrestation nous } \\
\text { en répondons tous à leurs Départemens. Le peuple est las de } \\
\text { vous voir ajourner son bonheur; il est encore entre vos } \\
\text { mains; sauvez-le ou il va se sauver lui-même.» } \\
\text { Le Président répond: «C'est dites-vous au nom du peuple de } \\
\text { Paris que vous venez de parler. Les autorités constituées, les } \\
\text { bons citoyens mettront sans doute au premier rang de leurs } \\
\text { devoirs le respect pour la représentation nationale. S'il y a } \\
\text { des traîtres parmi nous, il faut qu'ils soient découverts, jugés } \\
\text { et qu'ils tombent sous le glaive de la Loi. Vous venez de faire } \\
\text { à la Convention une demande que vous lui dites être la } \\
\text { dernière, la Convention l'examinera : elle pèsera les mesures } \\
\text { que sa sagesse lui commandera et fera exécuter avec courage } \\
\text { celles qui lui paraîtront nécessaires. La Convention vous } \\
\text { invite aux honneurs de la séance. }\end{array}$ \\
\hline
\end{tabular}




\begin{tabular}{|c|c|}
\hline $\begin{array}{l}\text { Sur cette pétition et les } \\
\text { observations auxquelles elle a } \\
\text { donné lieu, la Convention l'a } \\
\text { renvoyée au Comité de salut public. } \\
\text { On a demandé que le Comité de } \\
\text { salut public fasse son rapport } \\
\text { séance tenante. Sur quoi la } \\
\text { Convention a passé à l'ordre du jour } \\
\text { motivé sur le décret qui donne trois } \\
\text { jours au Comité de salut public pour } \\
\text { faire son rapport. }\end{array}$ & $\begin{array}{l}\text { Deux propositions sont faites : l'une de renvoyer la pétition } \\
\text { qui vient d'être lue au Comité de salut public; l'autre que le } \\
\text { Comité de salut public fasse maintenant et sans désemparer } \\
\text { un rapport sur les objets que cette pétition renferme. La } \\
\text { Convention décrète la première et passe à l'ordre du jour sur } \\
\text { la seconde motivée sur le décret qui accorde trois jours au } \\
\text { Comité de salut public pour préparer son rapport. }\end{array}$ \\
\hline
\end{tabular}

Dans les individus qui se présentent à la tribune de l'assemblée, la rédaction primitive voit «une délégation du Conseil général de la Commune de Paris» dont les propos lapidaires sont menaçants: la Convention doit mettre immédiatement les députés Girondins en arrestation sous peine d'une explosion incontrôlée de violences.

La réécriture voit tout autre chose: "une députation des autorités révolutionnaires constituées ", ce qui est exact, le Conseil général de la Commune de Paris n'étant que l'une de ces "autorités révolutionnaires constituées » siégeant au Comité Central révolutionnaire, l'instance fédérant les trente-trois sections parisiennes insurgées. Surtout, la réécriture met en scène un tout autre rapport de droit avec la députation. $\mathrm{Si}$ elle ne fait pas l'impasse sur l'expression de l'inquiétude des membres de l'assemblée, elle prend le temps d'expliciter comment la suspicion entre les représentants du peuple et ceux désignés comme les " pétitionnaires » se dissipe. Le recours à la vérification des pouvoirs, afin de s'assurer du caractère représentatif de la délégation, est une étapeclef dans le processus de reconnaissance mutuelle qui s'enclenche. La Convention l'exige. La députation l'accepte. C'est alors, après que la députation a donné la preuve de son adhésion au principe représentatif, que le président Mallarmé la considère digne de prendre la parole à la tribune de la Convention pour y lire une pétition aux accents dantonistes («Sauvez le peuple ou il va se sauver lui-même »), et bien plus modérée que le procès-verbal primitif ne l'admet: la demande de mise en arrestation des députés Girondins est la conséquence du fait qu'ils sont considérés «indignes » de la confiance publique (et non pas traîtres à la patrie). Cet ensemble fondamental d'interactions entre la représentation nationale et le Peuple est inconnu du procès-verbal primitif.

50 Le président se garde toutefois bien de qualifier ses interlocuteurs. Il exige d'eux le «respect» de la représentation nationale et affirme l'autonomie de l'agenda de la Convention - insurrection ou pas, le Comité de salut public ne fait pas son rapport "séance tenante ", mais, comme de droit, sous trois jours (en réalité quatre, puisqu'il s'agit du rapport prononcé par Barère le 6 juin). Et ce rapport est sans ambiguïté quant à l'autonomie de la souveraineté nationale. Paris est réduit à la taille d'une commune de la République; la Convention raffermie dans son incarnation de la souveraineté nationale :

C'est donc à la convention à ne jamais descendre de la place éminente où la puissance nationale l'a établie [...]. Que serait-ce une assemblée nationale qui, placée comme un dépôt sacré, au milieu d'une des communes de la république, ne serait obéie de personne, verrait à ses côtés des autorités subordonnées se paralysant elles-mêmes [...]. Que serait-ce donc qu'une assemblée [...] aux ordres $\underline{\text { d'un pouvoir inconnu aux lois }}^{77}$ ? [souligné par moi] 
51 l'adoption houleuse du procès-verbal, mais le jour du rapport de Barère], je crois que le côté droit [les Girondins] aurait permis aux patriotes d'y faire les changements qu'exigeait la vérité [...] », avait-il tort ? Le procès-verbal réécrit de la séance du 2 juin, lu à la tribune de la Convention par un membre du Comité des Décrets le 10 septembre, est adopté sans discussion. Mais le contexte est alors radicalement changé : cent vingtneuf députés Girondins ne siègent alors plus, quarante-et-un d'entre eux ont été mis en accusation devant le tribunal révolutionnaire, vingt sont condamnés à mort et exécutés le 31 octobre $1793^{78}$. Dans cette fin dramatique, comme le note M. J. Sydenham, deux circonstances ont joué un rôle déterminant : la conquête du Comité de salut public par la Montagne le 10 juillet 1793 ; l'assassinat de Marat par Charlotte Corday, trois jours plus $\operatorname{tard}^{79}$. Ce n'est qu'au prix d'un anachronisme, ce "péché capital de l'historien " (Lucien Febvre), que la fin tragique des Girondins est devenu le seul enjeu et la conclusion inexorable de la Journée du 31 mai-2 juin, bien davantage concernée par la mise au point juridique et rhétorique des modalités d'exercice du droit d'insurrection.

\section{Le 31 mai-2 juin : du bon usage du droit d'insurrection}

Le 27 mai, « au milieu du tumulte une voix puissante se fait entendre : "Je déclare que je résisterai seul à l'oppression de la majorité de la Convention [...] J'invite le peuple à se mettre dans la Convention nationale en insurrection contre tous les députés corrompus (Applaudi) [...] Je me mets en insurrection contre le président et contre tous les membres qui siègent dans la Convention (Applaudi) [...]. J'invite tous les députés montagnards à se rallier [...] ou de donner leur démission" $"{ }^{80} »$. La voix est celle de Danton. Il relaie, dans l'enceinte de la Convention, l'appel à l'insurrection lancé la veille aux Jacobins par Robespierre 㡠 《J'invite le peuple à se mettre dans la Convention nationale en insurrection contre tous les députés corrompus ${ }^{81}$ ». Qu'est-ce à dire ? Alors que, depuis 1789, remarque Garat, "nos déclarations des droits, nos loix, nos livres disent que l'insurrection est une chose sainte, [...] que s'ensuit-il ${ }^{82}$ ?». Ce n'est pas Robespierre qu'il convient de solliciter pour obtenir une réponse à cette question. Le leader Montagnard l'affirme sans détours : «Je suis incapable de prescrire au peuple les moyens de se sauver [...]. Ce n'est pas à moi d'indiquer ces mesures [...]. J'ai dit : il ne me reste plus d'autre devoir à remplir83 ".

53 «Insurrection »: si le mot apparaît dans L'Encyclopédie (1757-1758), le chevalier de Jaucourt, qui en rédige la notice, n'en constate pas moins sa désuétude ${ }^{84}$. La Révolution en réinvente l'usage et lui redonne une brûlante actualité, au point que l'Académie Française considèrera, dans son Supplément de 1798, « insurrection » comme un de ces mots nouveaux en usage depuis la Révolution.

54 Après Delisles de Sales et ses quatre longs chapitres consacrés à une lecture philosophique et politique de la notion d'insurrection dans Éponine ou de la République, paru en 1791, le vice-président de la section du Temple, Mandar, publie, en janvier 1793, un fort volume de plus de six cents pages intitulé: Des insurrections, ouvrage philosophique et politique sur les rapports des insurrections avec la liberté et la prospérité des empires $^{85}$. Dans cet ouvrage-clef, ainsi que l'analyse Pierre Serna, «l'irruption de force du plus grand nombre sur la scène politique, par le biais de l'insurrection, [n'est plus] la résultante de la seule colère désordonnée comme au matin du 14 juillet, mais la conséquence d'une stratégie politique mûrement réfléchie ${ }^{86} »$. Nimbé des violences du 
10 août, ruisselant du sang des massacres de Septembre, le mot "insurrection ", toutefois, continue de faire peur. «En recouvrant tous les droits, [l'insurrection] fait taire toutes les lois » écrit Garat: "et à moins qu'une nation n'ait une extrême simplicité de mœurs [c'est le peuple crétois qui est ici visé] [...] les époques des insurrections, destinées à châtier les grands crimes, sont aussi les époques où les grands crimes se commettent ${ }^{87}$ ». Comment faire pour que ce droit naturel universel du peuple dans un gouvernement libre qu'est l'insurrection puisse devenir un droit positif contrôlé, inscrit dans cette "grammaire de la raison" appelée de ses vœux par Mandar? Le 31 mai, les Montagnards résolvent le problème. Ils inventent, par l'entremise du procureur syndic général du département de Paris, Lhuillier, un proche de Robespierre, une insurrection d'un genre nouveau : " l'insurrection morale ». Garat écrit, dans ses Mémoires :

Les membres du département et le maire réitèrent souvent au Comité de salut public l'assurance que, tant qu'ils seront à leur poste, aucune violence ne sera commise dans cette insurrection ; c'est là que pour la première fois j'entendis sortir de la bouche de Lhuillier ce mot d'insurrection morale $[. . .]^{88}$.

Dans la bouche du juriste qu'est Lhuillier, dans l'enceinte de l'assemblée, à la tribune de la Convention, «insurrection morale » devient tout autre chose qu'un "mot» : un énoncé performatif, "un dispositif langagier permettant d'accomplir un certain type d'acte social ${ }^{89}$ » qui n'ambitionne pas « d'apaiser l'émeute » afin de maintenir un ordre de droit divin comme sous l'Ancien régime ${ }^{90}$, mais de normer le désordre, l'insurrection du Peuple, en vue de fonder la République démocratique.

Le vendredi 31 mai, à une heure très inhabituelle pour la Convention, 6 heures du matin, le président Mallarmé annonce à la centaine de députés présents «que de grands mouvements ont lieu dans la ville de Paris : le tocsin sonne, la générale bat dans presque toutes les sections et des citoyens semblent se disposer à tirer le canon d'alarme ${ }^{91}$ ». Un membre du Comité de salut public ajoute " qu'il a été fait des motions très incendiaires à la section de la Cité ${ }^{92} »$. C'est dans ce contexte alarmant que Lhuillier prend la parole à la tribune :

\begin{tabular}{|l|l|}
\hline $\begin{array}{l}\text { Intervention de Lhuillier au procès-verbal primitif } \\
\text { de la séance du } 31 \text { mai } 1793 \text { (AN, série C 253, dossier } \\
449-450)\end{array}$ & $\begin{array}{l}\text { Intervention de Lhuillier au procès-verbal réécrit de la } \\
\text { séance du } 31 \text { mai }^{93}\end{array}$ \\
\hline $\begin{array}{l}\text { Les membres du Département de Paris } \\
\text { paraissent à la barre. Le Procureur général } \\
\text { syndic déclare que le mouvement } \\
\text { extraordinaire qui se manifeste dans cette cité } \\
\text { doit être considéré comme une insurrection } \\
\text { morale, ayant pour objet la réparation des } \\
\text { calomnies répandues contre elle. }\end{array}$ & $\begin{array}{l}\text { Ladministration du Département de Paris est } \\
\text { extraordinaire qui se manifeste dans la ville de } \\
\text { Paris doit être considéré comme une insurrection } \\
\text { nombreuses calomnies depuis longtemps a pour objet la réparation de } \\
\text { répandues contre cette Cité. }\end{array}$ \\
\hline
\end{tabular}




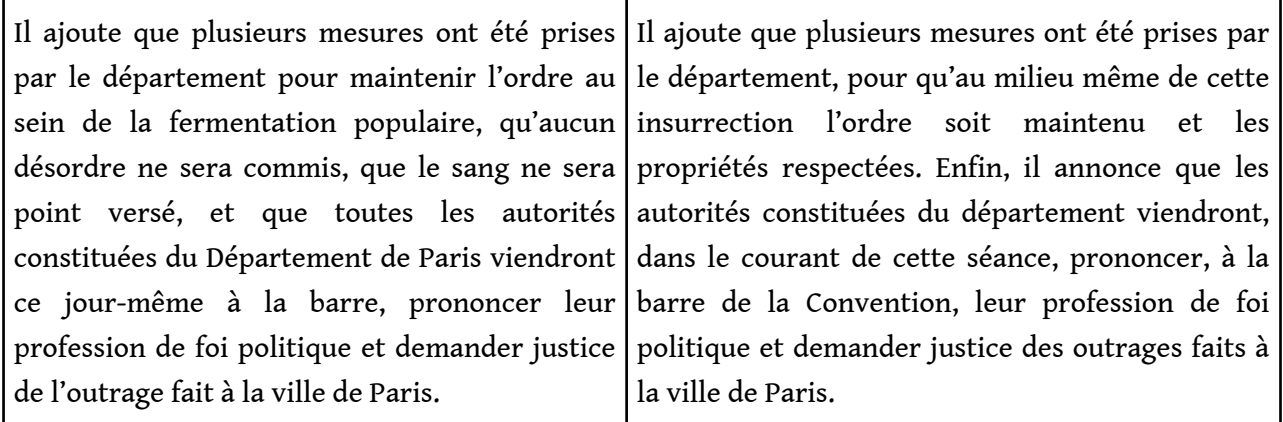

Il ajoute que plusieurs mesures ont été prises par le département, pour qu'au milieu même de cette insurrection l'ordre soit maintenu et les propriétés respectées. Enfin, il annonce que les autorités constituées du département viendront, dans le courant de cette séance, prononcer, à la barre de la Convention, leur profession de foi politique et demander justice des outrages faits à la ville de Paris.

Les Archives parlementaires fournissent à propos de cette intervention de Lhuillier une information capitale : à l'exception du Mercure universel, aucun compte-rendu publié dans les journaux, y compris Le Moniteur donc, ne la mentionne: "C'est au procèsverbal que nous l'empruntons ${ }^{94} "$, au procès-verbal réécrit, puisque c'est le seul que sollicitent les Archives parlementaires. Or, contrairement à ce qu'une lecture rapide du tableau, qui confronte les versions primitives et réécrites du procès-verbal, pourrait laisser croire, d'une version à l'autre, le texte attribué à Lhuillier subit une profonde transformation.

La version primitive, girondine, hésite sur la nature de l'événement. Il s'agit, une fois, d'une «insurrection morale», une autre fois, d'une "fermentation populaire ». La réécriture est beaucoup plus nette. Elle fait, à deux reprises, référence à l'insurrection morale. Se faisant, elle ne décrit pas un état de fait, mais institue un état de droit. L'expression "insurrection morale» se mue en qualification et recèle une force juridique qui va produire des effets dans la réalité ${ }^{0}{ }_{0}$ la suite des événements le montre ${ }^{95}$.

L'expression « insurrection morale » n'a toutefois retenu l'attention des historiens que pour être tournée en dérision 㺝 Pedro J. Ramirez parle de “coup d'état mou »" 㡠 ou pour déplorer sa faible portée explicative ${ }^{97}$. Seul Michelet fait exception. S’il n'accorde à l'insurrection morale d'autre importance que tactique ${ }^{98}$, il est toutefois le seul à en faire la clef de lecture de la Journée du 31 mai-2 juin, fournissant des détails précieux, recueillis en archives, sur la transformation de l'expression en mot d'ordre repris par les sections insurgées, l'opposant à «l'insurrection brutale» voulue par le Comité révolutionnaire de l'Évêchép9. L'analyse de Michelet permet de comprendre que la qualification « insurrection morale » imposée par le procès-verbal réécrit fut un enjeu de lutte, que la non-violence qui en résulta fut un choix politique ${ }^{100}$, toute opération de qualification emportant la disqualification de son antonyme: "Les sections [...] préféraient visiblement entre les deux insurrections, la modérée, la morale, c'est-à-dire la jacobine ${ }^{101}$. »

60 L'insurrection morale fixe la grammaire, l'ensemble des règles dans lesquelles les Montagnards, Lhuillier d'abord, Barère ensuite en tant que rapporteur du Comité de salut public, vont inscrire l'exercice du droit d'insurrection.

Le Peuple ne peut légalement et légitimement exercer le droit d'insurrection que dans le respect du droit de propriété et dans le respect de la sûreté des personnes. Ni pillage, ni sang : telles sont les contraintes que la qualification « insurrection morale » impose à l'exercice du droit d'insurrection. Placé dans un rapport de confiance avec le législateur 閲 «La Convention a reconnu elle-même la nécessité de cette insurrection 
[...]» dit Robespierre ${ }^{102}\left[{ }_{20}\right.$, le Peuple va consentir à appliquer ces contraintes, se les approprier au point de les faire siennes, voire même les revendiquer.

Le 3 juin, une affiche placardée sur les murs de Paris, tirée à 2000 exemplaires, tirage exceptionnel ${ }^{103}$, diffuse cette déclaration du Comité central révolutionnaire «formé par le Département de Paris, la Commune, et les commissaires des 48 sections de Paris envoiés avec des pouvoirs illimités et ceux des communes du département » (le chiffre de 48, qui est faux, a pour fonction d'insister sur l'unanimité des sections parisiennes) :

L'histoire ne présente aucune trace d'une révolution conformée sans répandre de sang. Nos voisins les Anglais qui se croyent libres depuis bien des années n'ont fait encore aucun mouvement populaire qu'il n'est [sic] été souillé par la mort d'un grand nombre d'individus. Voilà donc enfin l'exemple d'une révolution faite par la force imprescriptible de la raison seule, sans passion et dans laquelle personne n'a été sacrifiée ${ }^{104}[\ldots]$.

Quant à Pache, le maire de Paris, il loue, dans une lettre publique, elle aussi affichée sur les murs de la ville, la « sainte insurrection » de ceux qui « ont prouvé que ce n'était ni $\mathrm{du}$ sang, ni le pillage, ni l'anarchie qu'ils demandaient, mais bien des Loix, la Liberté, l'Égalité, l'indivisibilité de la République ${ }^{105}[\ldots]$ ".

En synchronie, mais dans une autre arène, l'enceinte de la Convention, le législateur met en scène le bon peuple insurgé. Le $1^{\mathrm{er}}$ juin, Barère loue à la Convention «l'étonnant spectacle d'une insurrection dans laquelle la vie et les propriétés ont été aussi sûrement protégées que dans le meilleur ordre social ${ }^{106}$ ». L'utilisation du passé invite à mettre un terme à une insurrection toujours en cours dont la détermination ne faiblit pas: "Je tiens de plusieurs citoyens dignes de foi », rapporte le député Girondin Saladin, «qu'Henriot [le commandant de la Garde nationale au parler sans-culotte ${ }^{107}$ ], passant dans les rangs et adressant la parole à chaque peloton, leur disait : "Il ne faut pas verser le sang, mais il ne faut pas se retirer que les vingt-deux membres [les députés girondins] ne soient livrés" 108 ». Si ces derniers ne sont pas " livrés », le peuple insurgé n'en obtient pas moins satisfaction.

Par décret du 2 juin 1793, vingt-neuf députés Girondins sont mis en état d'arrestation à leur domicile « sous la sauvegarde du peuple français et de la Convention nationale ${ }^{109}$ ". Il convient de citer exactement les termes de la sanction qu'inventent les légistes de la Montagne pour comprendre l'arche d'alliance qu'elle institue en termes de dignité entre le Peuple et l'Assemblée, tous deux appelés à parts égales à veiller à l'exécution du décret.

La mise en état d'arrestation est une sanction jusqu'alors inconnue. Le 2 juin, seul le décret d'accusation, en faveur duquel se prononce Robespierre, est de droit. BillaudVarenne le fait remarquer à l'assemblée ${ }^{110}$. Une partie de la Montagne 㡠 Danton, Barère et Couthon sont du nombre ${ }^{111}$ [⿰氵⿴囗⿱一一⿻口卄日, , ne veut pas de cette solution-là.

Que signifie la "mise en état d'arrestation "? Cette "garde à vue à domicile ", selon l'heureuse expression de Michel Biard ${ }^{112}$, est désignée, au procès-verbal réécrit, comme une "mesure de sûreté générale ». C'est la première attestation d'un nouveau type de sanction, qui est codifiée dans la Constitution de l'an ${ }^{113}$, et appliquée à une large échelle dans la loi des suspects (7 et 17 septembre 1793). Le 2 juin, la mise en état d'arrestation vise moins à punir qu'à protéger les députés Girondins 5 [ [Sauvez vos collègues; décrétez leur arrestation » dit le député Richou ${ }^{114}{ }_{20}$ et à préserver l'intégrité de la représentation nationale. Décréter la mise en accusation des députés Girondins signifiait, à cause et aux termes du décret du 5 avril $1793^{115}$, les renvoyer devant le 
tribunal révolutionnaire. Dans ses Mémoires, le conventionnel Baudot rappelle l'« accord tacite dans le Comité [de salut public] pour tenir [les Girondins] éloignés de la Convention sans les livrer au tribunal révolutionnaire. Cambon me l'a assuré souvent ${ }^{116}$ ». Marat, déféré au tribunal révolutionnaire en avril 1793, en était ressorti acquitté et la tête couverte d'une couronne civique; en juillet 1793, le taux d'acquittement des prévenus devant le tribunal révolutionnaire est supérieur à $70 \%$ : les Girondins se savent à la fois innocents et trop bons rhéteurs pour ne pas imaginer être, eux aussi, acquittés. Reste qu'il est des procès auxquels il vaut mieux échapper. Lanjuinais ne l'ignore pas. La lettre qu'il envoie à la Convention le 3 juin l'atteste :

Citoyens mes collègues,

Je viens d'être mis en état d'arrestation chez moi, ce matin, à 9 heures, en exécution de votre décret, je suis gardé par deux gendarmes [...]. Vous avez cédé hier à la nécessité : je vous remercie d'avoir empêché peut-être par votre condescendance de plus grands attentats $^{117}$ [...] [souligné par moi].

Lue par le secrétaire de la séance, la lettre de Lanjuinais est accueillie, peut-on lire au Moniteur, par « de violents murmures ». D’incrédulité probablement: Lanjuinais a été l'orateur de la Gironde le plus radicalement anti-Montagnard. Le lendemain de l'insurrection qui signe la défaite parlementaire de la Gironde, il remercie ses ennemis politiques déclarés ? Lanjuinais est fort bon juriste. Il sait que la mise en arrestation est une sanction infiniment plus modérée que la mise en accusation. Est-ce pour faire oublier cette lettre qu'il orchestre l'incident de séance qui l'a opposé au Montagnard Legendre, incident appelé à fixer l'image de la violence déchaînée des Montagnards contre les Girondins pour la postérité ? Louis Legendre s'avance vers la tribune et menace Lanjuinais, peut-on lire aux Archives parlementaires :

Lanjuinais: Legendre, venez-donc me jeter du haut en au bas de la tribune. (Violentes protestations sur la Montagne) Comment voulez-vous assurer la liberté de la représentation nationale, lorsqu'un député vient me dire à cette barre: "Jusqu'à extinction des scélérats qui te ressemblent, nous remuerons et agirons ainsi » (Nouvelles interruptions) ${ }^{118}$.

Lanjuinais rapporte cette scène en ces termes dans un Fragment de mémoire publié en 1825 :

Ce jour-là [...] Legendre, boucher, faisant avec effort le geste du merlin [masse pour assommer les bœufs], me menaça et cria : "Descends ou je vais t'assommer. » Son geste m'inspira ; je le fis taire et s'asseoir en lui disant à regret : " Fais décréter que je suis bœuf et tu m'assommeras. » Revenu bientôt de son trouble extrême, il vient m'assaillir ${ }^{119}[. .$.$] .$

70 Pedro J. Ramirez fait justement observer que le 2 juin étant un dimanche, les journaux ne paraissent pas : «Aucun récit contemporain ne recueillit les détails de l'incident [...]. Mais tous les historiens qui ont mentionné cet épisode ont ajouté foi à la version de Lanjuinais, dramatiquement reconstruite au milieu du XIX ${ }^{\mathrm{e}}$ siècle dans le tableau de Charles-Louis-Lucien Muller qui occupe aujourd'hui une place d'honneur à l'assemblée nationale ${ }^{120} »$. 


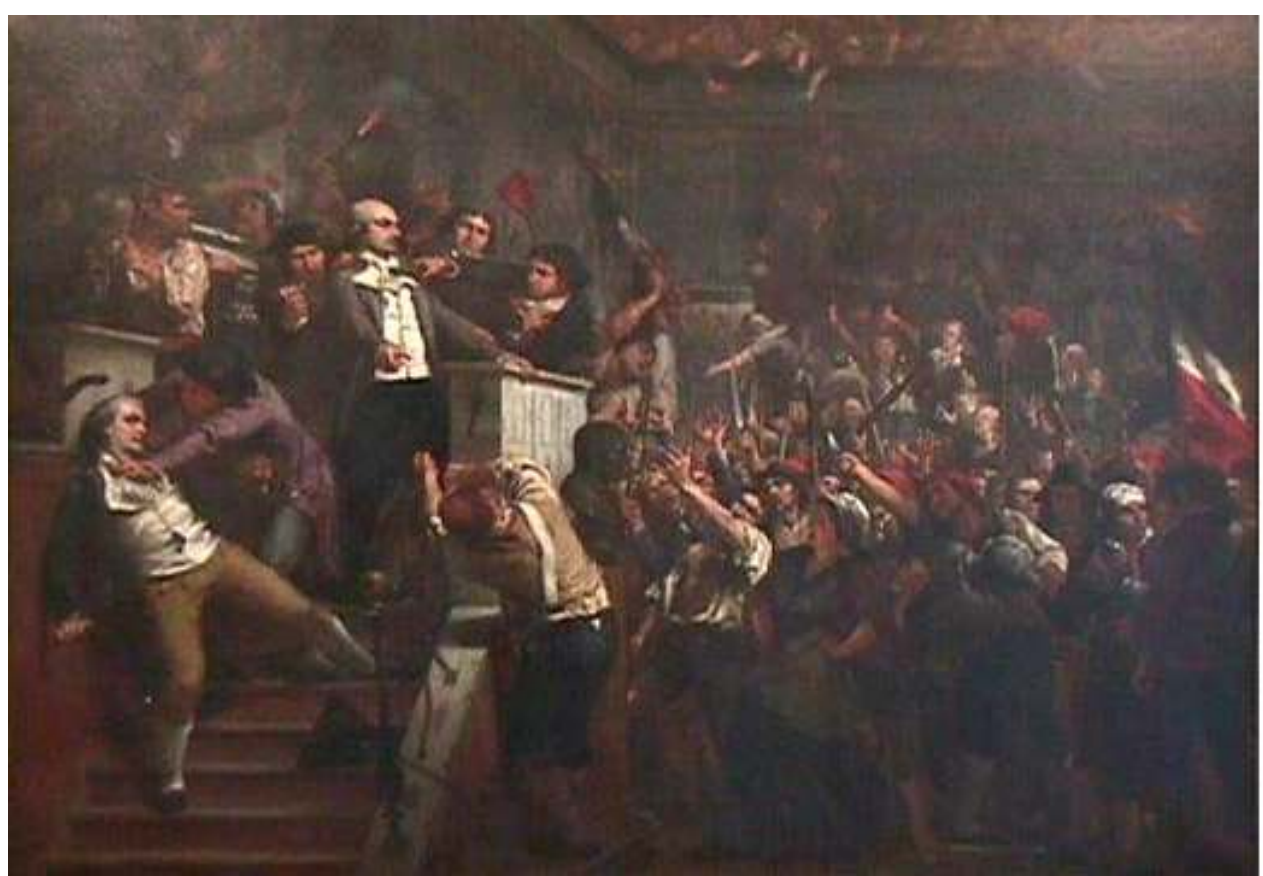

Charles-Louis-Lucien Muller, « Lanjuinais à la tribune de la Convention nationale » (1868, huile sur toile), https://commons.wikimedia.org/wiki/File:Muller__Lanjuinais_\%C3\%A0_la_tribune_de_la_Convention.jpg

71 C'est le 8 juillet 1793, lors du rapport que Saint-Just prononce au nom du Comité de salut public, "sur les trente-deux membres ${ }^{121}$ de la Convention détenus en vertu du décret du 2 juin ", que le sort des Girondins bascule. Seuls neuf des vingt-neuf députés girondins sont alors présents à leur domicile. Les autres ont pris la fuite et rejoint les départements où ils fomentent des troubles 㔵 « attisent la guerre civile» selon les mots de l'époque ${ }^{122}$.

En fuite, les députés girondins peuvent être assimilés à des contumaces traîtres à la patrie. Le Comité de salut public, fait alors, et seulement alors, ce qu'il s'était obstinément refusé à faire, par l'entremise de Barère, le 2 juin. Le 8 juillet, Saint-Just transforme la responsabilité politique des Girondins en responsabilité pénale. Jacqueline Chaumié rappelle que le rapport de Saint-Just "surprit par son indulgence ${ }^{123} »$. La radicalité, en la matière, ne relève pas de la psychologie (fut-elle celle de Saint-Just), mais du droit. Saint-Just ne rapporte pas. Il requiert: contre les neuf députés girondins "en état de rébellion", la mise hors de la loi ; contre cinq autres, la mise en accusation devant le tribunal révolutionnaire ${ }^{124}$. Suite au rapport d'Amar, le 3 octobre 1793, quarante-et-un députés Girondins seront renvoyés devant le tribunal révolutionnaire ${ }^{125}$. Le 31 octobre 1793 , le tribunal révolutionnaire prononcera contre les Girondins vingt condamnations à mort exécutées ( $c f$. supra).

Si les hommes de l'an III ne reviennent pas sur les Déclarations des droits de 1793, ou à la marge, y puisant même l'idée d'une Déclaration des devoirs, empruntée au décret instaurant la fête de l'Être suprême rédigé par Robespierre ${ }^{126}$, le droit d'insurrection, en revanche, est rayé de la Déclaration des droits et des devoirs de l'homme et du citoyen, préambule de la Constitution de l'an III :

Vous conviendrez [dira le rapporteur Boissy d'Anglas, le 5 messidor an III (23 juin 1795) à la Convention] qu'il est immoral, impolitique et excessivement dangereux d'établir dans une constitution un principe de désorganisation aussi funeste que celui qui provoque l'insurrection contre les actes de tout gouvernement. Vous 
conviendrez qu'il est impossible d'énoncer avec précision le cas où l'insurrection est légitime et devient un droit, et que, cependant, s'il est une circonstance dans laquelle une disposition vague puisse être funeste, c'est celle-là. Mais il est une vérité constante, c'est que lorsque l'insurrection est générale, elle n'a plus besoin d'apologie et que, lorsqu'elle est partielle, elle est toujours coupable. Nous avons donc supprimé l'article 35, qui fut l'ouvrage de Robespierre, et qui, dans plus d'une circonstance, a été le cri de ralliement des brigands armés contre vous [...] ${ }^{127}$.

De profundis plutôt que programme : lors des Journées de germinal (mars) et de prairial (juin) an III, revendiquant du Pain et l'application de la Constitution de l'an I, le peuple de Paris a fait l'expérience de l'insurrection, sans droit à l'insurrection lui permettant d'exercer sa souveraineté et de faire entendre de ses revendications. « Pour la première fois depuis 1789 , le peuple se trouvait isolé, ne trouvant aucun élément de la bourgeoisie auquel il put se rallier, sur le plan social et politique ${ }^{128}$. Le rêve de République démocratique surgit de et incarné par la Journée du 31 mai-2 juin avait vécu.

\section{Conclusion}

La journée du 31 mai-2 juin n'est pas un coup d'état « prototype de tous les coups d'état ultérieurs, jusqu'au 18 brumaire ${ }^{129}[. .$.$] ", mais un coup d'estat appelé à demeurer unique$ dans les annales de la République : un coup de majesté du Peuple. Ce coup d'estat posa les fondements d'une République démocratique intégrant dans son droit public la coexistence de la souveraineté nationale (attribuée aux représentants du peuple) et de la souveraineté populaire (incarnée par le droit d'insurrection). Ce en quoi la République démocratique signifiait qu'elle était, davantage qu'un régime de gouvernement, une civilisation du droit où l'efficacité de la norme (les Déclarations des droits) était liée à un récit fondateur (la réécriture du procès-verbal des séances de la Convention) instaurant une grammaire d'action (l'exercice, sous contraintes juridiques et sans violences contre les personnes et les biens, du droit d'insurrection). En parlant droit au Peuple dans l'enceinte de la Convention et en réécrivant les procès-verbaux, le Législateur est parvenu non seulement à énoncer les contraintes (ni pillage, ni sang) légitimant le bon usage du droit d'insurrection ${ }^{130}$, mais aussi à ce que le Peuple consente à ce bon usage d'un droit nouveau.

Le droit d'insurrection, qui semble avoir « subi l'excès d'indignité qui s'attache à tout ce qui apparaît peu ou prou lié à la période de la Terreur ${ }^{131}$ ", n'a pas vocation à justifier n'importe quel soulèvement populaire. Il est le corollaire de cette "insurrection morale ", de cette invention des légistes Montagnards, dont la Journée du 31 mai-2 juin atteste qu'il ne s'agit pas d'une utopie mais d'un dispositif, d'un ensemble résolument hétérogène, eût dit Michel Foucault, comportant ici des discours, des lois, des contraintes, mis en réseau au sein d'une relation de pouvoir afin de répondre à une situation d'urgence ${ }^{132}$ : traduire instantanément les revendications du Peuple insurgé dans la langue du droit (la mise en arrestation plutôt que la mise en accusation des députés Girondins).

77 «Les couloirs qui conduisaient à la partie droite de la salle [celle où siègent les Girondins] étaient obstrués par quelques femmes qui y ont pénétré, pour attendre le résultat de la délibération; [...] elles avaient témoigné le désir qu'aucun député ne sortit avant que la délibération ne fut prise ; mais [...] leur ayant parlé le langage de la Loi, elles s'étaient retirées ${ }^{133}$ ». Savoir parler droit au Peuple pour faire que "l'explosion [...] tourne au profit de la chose publique » : la formule est de l'un des acteurs essentiels 
de la Journée du 31 mai-2 juin, Georges Danton, celle peut-être qui résume le mieux ce coup d'estat ${ }^{134}$ où l'on ne devait déplorer qu'un seul incident de personne, l'évanouissement (de courte durée) du commandant de la section armée de la Buttedes-Moulins, Raffey ou Raffet :

On apprend que le généreux commandant de la Butte-des-Moulins [...] vient de tomber, frappé d'un coup de sang. La stupeur succède aux élans de la joie ; on croit qu'il expire. On n'ignore pas que sa mort n'était due qu'à ses fatigues ; depuis trois jours, il ne s'était pas couché un seul instant [...] un chirurgien accourt ; il lui ouvre la veine; il répond de sa vie. Alors les cris de vive la République, d'anathème à l'anarchie, retentissent de toutes parts.

\section{NOTES}

1. Louis de ROUVROY, duc de SAINT-SIMON, «La journée des Dupes », Variétés historiques et littéraires, t. IX, 1859, p. 309-326, https://fr.wikisource.org/wiki/La_Journ\%C3\%A9e_des_Dupes

2. Michel VovelLe, «Préface ", dans Jules MICHELET, La Révolution française. Les grandes journées, Paris, Le Livre de Poche, 1988, p. 5.

3. Décret du 18 mai 1793 «qui établit dans le sein de la Convention une commission extraordinaire, chargée de prendre connaissance de tous les complots tramés contre la liberté dans l'intérieur de la République, et contre la représentation nationale », Collection Baudouin, vol. mai 1793, p. 165. Les décrets cités de la collection Baudouin ont été numérises et doivent être consultés à : https://artflsrv03.uchicago.edu/philologic4/revlawall1119/

4. Je reprends ici, sans la discuter, la qualification "Girondin » qui a suscité des controverses scientifiques. Voir en particulier Alison PATRICK, "Political division in the French National Convention 1792-1793 », The Journal of Modern History, vol. 41, nº 9, December 1969, p. 421-474 et Theodore A. DI PADOVA, "The Girondins and the Question of Revolutionary Government ", French Historical Studies, vol.9, $\mathrm{n}^{\circ}$ 3, Spring 1976, p. 432-434 et Anne de MATHAN, Girondins jusqu'au tombeau. Une révolte bordelaise dans la Révolution, Bordeaux, Éditions du Sud-Ouest, 2004, p. 112 et sq.

5. Ernest LAVISSE (dir.), Histoire de la France contemporaine depuis la Révolution jusqu'à la paix de 1919, t. II, par Georges PARISET, La Révolution (1792-1799), Paris, Hachette, 1921, p. 85-164. Voir aussi : Patrice GUENIfFeY, La Politique de la Terreur. Essai sur la violence révolutionnaire 1789-1794, Paris, Gallimard, coll. « Tel », 2003, p. 247 et Jean-Clément MARTIN, "Le recours au coup d'état ", dans ID., Violence et Révolution. Essai sur la naissance d'un mythe national, Paris, Seuil, coll. «L'univers historique ", 2006, p. 164-165.

6. MORTIMER-TERNAUX, Histoire de la Terreur 1792-1794, Paris, Michel Lévy, 1869, t. VII, p. 425 et p. 299 et $s q$.

7. Pedro J. RAMIREZ, Le coup d'État. Robespierre, Danton et Marat contre la démocratie, Paris, Vendémiaire, 2014, p. 13. Patrick Lagoueyte signale que la traduction littérale du titre eût dû être : Le Premier naufrage. Le coup d'état de Robespierre, Danton et Marat contre le premier parlement élu au suffrage universel masculin, dans Patrick LAGOUEYTE, Les coups d'État. Une histoire française, Paris, CNRS Éditions, 2021, p. 168. Du livre de Ramirez, Antoine de BAECQUE écrit: «La capacité interprétative de ces mille pages serrées nous laisse plus dubitatif », Le Monde, 10 novembre 2014 ; 
dans les Annales historiques de la Révolution française, Les Conventionnels, juillet-septembre 2015, $\mathrm{n}^{\circ} 381$, p. 207-209, Alexandre GUERMAZI signe une critique sévère à laquelle je souscris.

8. Moris SLAVIN, The Making of an Insurrection. Parisian Sections and the Gironde, Cambridge et Londres, Harvard University Press, 1986, p. 162-163.

9. Patrick LAGouEYTE, «Les Girondins éliminés par un coup d'état? ", dans ID., Les coups d'État, op. cit., p. 162-172.

10. Carl sснмітт, « La formation de l'esprit français par les légistes » [1942], dans Carl schmitt, Du Politique. Légalité et légitimité et autres essais, textes choisis par Alain de BENOIST, Grez-sur-Loing, Pardès, 1990, coll. «Révolution conservatrice», p. 202. Je remercie Olivier Beaud de m'avoir fait lire cet article.

11. Ibid., p. 186.

12. Michel TROPER, "Souveraineté et représentation", dans Manuela ALBERTONE et Dario CASTIGLIONE (dir.), Le défi de la représentation. Langages, pratiques et figuration du gouvernement, Paris, Classiques Garnier, 2018, p. 84.

13. Archives parlementaires (désormais AP), t. 66, séance du 6 juin 1793, p. 109.

14. Lucien JAUME, «Le projet constitutionnel de Condorcet : redéfinir la volonté générale », dans ID., Le discours jacobin et la démocratie, Paris, Fayard, 1989, p. 313-318.

15. Alain LAQUIEZ, "Le coup d'état sous la Révolution française ", dans Christophe BOUTIN et Frédéric Rouvillois (dir.), Le coup d'état. Recours à la force ou dernier mot du politique?, Paris, François-Xavier de Guibert, coll. « Combats pour la liberté de l'esprit », 2007, p. 77-78.

16. AP, t. 66, séance du 2 juin 1793 , p. 708.

17. Sophie WAHNICH, "Résistance à l'oppression et devoir d'insurrection pendant la Révolution française ", dans Jean-Claude ZANCARINI (dir.), Le droit de résistance XII ${ }^{e}-\mathrm{XX}^{e}$ siècle, Paris, ENS Éditions, 1999, p. 261.

18. Matthias MALBLANC, «Un objet juridiquement insaisissable: le droit de résistance à l'oppression ", Jurisdoctoria, n 12, 2015, p. 17-19: "La démarche positiviste que cette étude se propose d'adopter ne permet pas de saisir juridiquement le droit de résistance à l'oppression » qui porte « la marque d'un certain romantisme révolutionnaire ». Voir aussi Éric DESMONDS, Droit et devoir de résistance en droit interne. Contribution à une théorie du droit positif, Paris, LGDJ, 1994, p. 65 et Joseph-Barthélemy et Paul DuEz, Traité de droit constitutionnel [1933], Paris, Éditions PanthéonAssas, 2004, p. 248: "La théorie de la résistance à l'oppression est une théorie politique non juridique ».

19. Florence BENOITT-RHOMER et Patrick WASCHMANN, «La résistance à l'oppression dans la Déclaration ", Droits. Revue française de théorie juridique, $\mathrm{n}^{\circ}$ 8, 1988, p. 90.

20. Art. 2: «Le but de toute association politique est la conservation des droits naturels et imprescriptibles de l'homme ; ces droits sont la liberté, la propriété, la sûreté et la résistance à l'oppression ».

21. Art. 1 : «Les droits de l'homme en société sont l'égalité, la liberté, la sûreté, la propriété, la garantie sociale et la résistance à l'oppression. ». Voir AP, t. 65, séance du 29 mai 1793, p. 579.

22. Art. 33 : «La résistance à l'oppression est la conséquence des autres droits de l'homme »; art. 35 : «Quand le gouvernement viole les droits du peuple, l'insurrection est pour le peuple, et pour chaque portion du peuple, le plus sacré des droits et le plus indispensable des devoirs. ». Voir AP, t. 67, séance du 23 juin 1793, p. 106.

23. William Doyle, France and the Age of Revolution. Regimes Old and New from Louis XVI to Napoleon Bonaparte, London, L.B. Tauris and Co Ltd, 2013, p. 101-102.

24. Patrick LAGOUEYTE, Les coups d'état, op. cit., p. 12.

25. Alain LAQUIEZ, « Le coup d'état sous la Révolution française », art. cité, p. 79.

26. Maurice Agulhon, Coup d'état et République, Paris, Presses de Sciences Po, 1997, p. 8-15. 
27. Merlin de DOUAI, «Procès-verbal ", dans Répertoire universel et raisonné de jurisprudence, Paris, Garnery Libraire, 1827-1828, t. 13, p. 346.

28. Robert M. COVER, «La session 1982 de la Cour Suprême. Préface Nomos et narration », dans Le Droit dans tous ses états à travers l'œuvre de Robert M. Cover, traduction Françoise MICHAUT, Paris, L'Harmattan, 2001, p. 70.

29. L'explication de la majuscule au mot « peuple » est infra.

30. Sur les rapports a priori exécrables entre Robespierre et Condorcet, voir Hervé LEUWERS, Robespierre, Paris, Fayard, 2014, p. 219. Je plagie le titre d'un article de F. BORNAREL, "Danton collaborateur de Barère ", La Révolution française. Revue d'histoire moderne et contemporaine, $\mathrm{t}$. XIX, juillet 1890, p. 185-188. C'est Danton qui est l'auteur d'une partie du rapport que Barère fait au nom du comité de Salut Public à la Convention le 29 mai 1793

31. Alain LAQUIEZ, « Le coup d'état sous la Révolution française », art. cité, p. 77-78.

32. Le Moniteur, t. xvI, séance du 27 mai, p. 491.

33. Henri WALlon, La Révolution du 31 mai et le fédéralisme en 1793 ou La France vaincue par la Commune de Paris, Paris, Hachette, 1886, t. I, p. 227.

34. Le Moniteur, t. xvI, séance du 27 mai, p. 492.

35. Grigore GEAMANU, La résistance à l'oppression et le droit à l'insurrection, Paris, Les Éditions DomatMonchrestien, 1933, p. 142.

36. Le Moniteur, t. XVI, séance du 17 avril 1793, p. 174. Le tome 62 des AP qui contient cette séance n'est pas disponible en version numérique sur Gallica.

37. Titre VIII du projet de Constitution girondine : « De la Censure du Peuple sur les Actes de la Représentation Nationale, [...] » consultable à : https://mjp.univ-perp.fr/france/co1793pr.htm\#8 38. Cité in Lucien JAUME, Les Déclarations des droits de l'homme, op. cit., p. 232 et art. 32 du projet Condorcet de Déclaration des Droits, cité.

39. Présentation de l'art. 31 des «articles additionnels" proposés par Robespierre en compléments des articles rédigés par Condorcet, AP, t. 63, séance du 24 avril 1793, p. 197 et sq. Sur l'art de la formule et la recherche de «l'expression juste » par Robespierre, voir Hervé LEUWERS, Robespierre, op. cit., p. 263-264.

40. Lucien JAUME, Les Déclarations des droits, op. cit., p. 227-228 et p. 299.

41. Lucien JAUME, Le Discours jacobin et la démocratie, Paris, Fayard, 1989, p. 315.

42. Véronique CHAMPEIL-DESPLATS et Michel TROPER, «Proposition pour une théorie des contraintes juridiques", dans Véronique CHAMPEIL-DESPLATS, Michel TROPER et Christophe GRZEGORCZYK (dir.), Théorie des contraintes juridiques, Paris, Bruylant/LGDJ, 2005, p.12. Sur la coexistence des Déclarations des Droits girondine et montagnarde, voir cette remarque du ministre de la Justice, Gohier, le 18 juillet 1793 : «observe à la Convention qu'il existe deux Déclarations des droits de l'homme qui ont été décrétées, l'une le 29 mai, l'autre le 24 juin, qui ne peuvent pas subsister dans le dépôt de la législation française; ce ministre demande en conséquence que la première déclaration soit annulée, pour éviter toute confusion et qu'il soit autorisé à retirer les exemplaires dont l'envoi a été fait ", AP, t. 69, p. 130. Gohier réitèrera sa demande le 20 juillet (ibid., p. 148). Très curieusement, le Comité de Législation, sollicité, ne s'exprime pas.

43. [Jean-François VARLET], Déclaration solennelle des droits de l'homme dans l'état social, Paris, L'an premier de la vérité, 1793, p. 5 et p. 20.

44. Michel TROPER, «Souveraineté et représentation », art. cité, p. 86. Robespierre s'efforcera, en vain, de ranimer le mandat impératif lors du débat constitutionnel du 16 juin, dans Lucien JAUME, Le discours jacobin et la démocratie, op. cit., p. 333-334.

45. André CASTALDO, Les méthodes de l'assemblée constituante, Paris, PUF, coll. «Léviathan », 1989, p. 107 et p. 270, note 69 : Suite à la fuite du roi par Varennes, le 21 juin 1791, alors que le procèsverbal est habituellement rédigé à tour de rôle par l'un des secrétaires de l'assemblée, en fonction des notes prises par lui en séance, Barnave adjoint « à celui des secrétaires qui a pris les 
notes du procès-verbal, six commissaires chargés avec lui de la rédaction du procès-verbal [...]. Ils seront autorisés à introduire dans ces décrets les quelques changements d'expression qu'ils croiront nécessaires » [souligné par moi]. Il n'y a pas de réécriture intégrale donc.

46. Voir la brochure spécifiquement dédiée par Baudouin aux procès-verbaux réécrits : Procèsverbaux de la Convention nationale. Séances des 27, 31 mai et 2 juin 1793, Paris, Imprimerie nationale, 1793.

47. DURAND DE MAILlANE, Histoire de la Convention nationale, Paris, Baudouin Frères, 1825, p. 115. Consulter le texte du procès-verbal du 2 juin reproduit par lui qu'il reproche au Montagnard Thuriot d'avoir corrigé, alors que la réécriture a été faite par le comité des décrets, et non par tel ou tel député, ibid., p. 122.

48. Mortimer TeRnauX, Histoire de la Terreur 1792-1794, Paris, Michel Lévy Frères, 1869, t. VII, p. 353, note 1. Ce point concernant la signature des décrets n'est pas exact. Aucun texte ne prévoit qui doit signer les procès-verbaux adoptés plus d'une semaine après leur rédaction. Ce ne sera que le 29 prairial an II (17 juin 1794) que la Convention décidera que les « anciens procès-verbaux », non signés en leur temps par des présidents décédés ou absents, le seront selon une procédure, de fait, inventée pour les procès-verbaux réécrits de la journée du 31 mai- 2 juin. Décret du 29 prairial an II «portant qu'il sera nommé un ancien présidens et quatre anciens secrétaires pour signer les expéditions des procès-verbaux qui doivent être déposés aux archives et livrés à l'impression, en remplacement des présidens ou secrétaires morts ou absens ». Collection Baudouin numérisée consultable à la date des décrets sur le site: https:// artflsrv03.uchicago.edu/philologic4/revlawall1119/

49. Henri WALlon, La Révolution du 31 mai, op. cit., p. 225. Le procès-verbal original et le procèsverbal réécrit se trouvent placés à la suite l'un de l'autre dans les cartons de la série $C / 253$, dossiers 449-450 et C/256, dossier 490-492 et 495-496 des Archives nationales (désormais AN).

50. Voir l'article de synthèse de Françoise BRUNEL et Corine GOMEZ-LECHEVANTON, « La Convention nationale au miroir des Archives parlementaires ", Annales historiques de la Révolution française, Les Conventionnels, $\mathrm{n}^{\circ}$ 381, juillet-septembre 2015, p. 16 et l'article, très critique envers les $A P$, que signe Jules GUIFFREY, "Étude sur la collection publiée sous le titre de Archives parlementaires ", La Révolution française revue historique, t. 16, janvier-juin 1889, p. 11.

51. Le tome 65, publié en 1905, des AP qui concerne les séances parlementaires qui forment la Journée du 31 mai-2 juin indique, dans une note en bas de page, qu'est utilisé, pour la séance du 31 mai, un matériau " emprunté un peu à tous les journaux » associé au procès-verbal, rédigé par le Comité des Décrets, adopté par la Convention le $1^{\mathrm{er}}$ septembre 1793. Donc le procès-verbal réécrit. Mais des problèmes soulevés par la réécriture et de ses variantes par rapport au procèsverbal primitif, pas un mot. Voir AP, t. 65, séance du 31 mai 1793, note 1, p. 638.

52. Dominique Joseph GARAT, Mémoires sur la Révolution ou Exposé de ma conduite dans les affaires et les fonctions publiques, Paris, Imprimerie de J. J. Smits et $C^{\text {ie }}$, an III de la République, p. 45.

53. Jules GUIFFREY, «Étude sur la collection publiée sous le titre de Archives parlementaires », art. cité, p. 11.

54. Décret sans titre du 29 mai 1789. Collection Baudouin numérisée.

55. La Convention peut être en retard sur l'adoption des procès-verbaux. Voir par exemple AP, t. 65 , séance du 22 mai 1793, p. 207 où sont successivement adoptés les procès-verbaux des séances du 16 mai, du 21 et du 22 mai), mais en retard de quelques jours seulement.

56. André CASTALDO, Les méthodes de travail de la Constituante, op. cit., p. 272.

57. Ibid., p. 271.

58. Amédée OUTREY, «La notion traditionnelle de titre et les origines de la législation révolutionnaire sur les archives. La loi du 7 septembre 1790 », Revue historique de Droit français et étranger, 1955, p. 441. 
59. «Un membre a fait observer que le Bureau des secrétaires de la Convention est toujours embarrassé par des commis de l'imprimeur et des journalistes qui se saisissent des minutes des décrets et des adresses pour les coppier [sic] ; qu'il en arrive que l'imprimeur de la Convention les imprime aussitôt avant leur correction et révision, d'où il arrive qu'il y a des fautes et imperfections et contresens, que souvent les adresses et pièces jointes sont égarées ce à quoi il convient de remédier. Le Comité trouvant l'observation juste, arrête que le citoyen Mounel sollicitera, de la Convention, un décret qui défende à l'imprimeur national d'imprimer aucun décret ni adresse que sur ces expéditions du bureau des décrets, visées par l'inspecteur des procès-verbaux, du président et des secrétaires de la Convention ». Source : Comité des Décrets, AN, cote : D/I\$1/2, $76^{\mathrm{e}}$ séance, 28 juin 1793.

60. Décret du 12 juillet 1793 «qui ordonne le transport de la bibliothèque des ci-devant avocats dans celle du comité de législation, et accorde des récompenses aux auteurs d'ouvrages utiles sur les lois civiles et criminelles » : art. $2:$ «L'imprimeur de la Convention fera remettre sans délai entre les mains d'un secrétaire-commis désigné par le comité de législation un exemplaire cartonné des procès-verbaux des Assemblées constituante et législative et de la Convention nationale [...]. Il continuera à fournir des volumes des procès-verbaux et des lois à mesure qu'ils paraîtront [...] ». Source : Collection Baudouin numérisée.

61. Bertrand BARÈRE DE VIEUZAC, Rapport au nom du comité de Salut Public "relatif aux évènements des 31 mai dernier et jours suivant ", 6 juin 1793, p. 110.

62. AP, t. 66, séance du 19 juin 1793, p. 688.

63. Séance du 27 mai 1793, dans Procès-Verbal de la Convention nationale, Paris, Imprimerie nationale, 1793, t. XI, p. 194.

64. AP, t. 72, séance du 12 août 1793, p. 76.

65. À partir d'août 1793, le Comité des Décrets se substitue aux secrétaires de la Convention pour la rédaction des procès-verbaux, quand besoin est: "Le même comité des décrets rédigera le procès-verbal du 15 juillet, le secrétaire chargé de cette rédaction étant malade ", AP, t. 73, p. 632. Ce n'est que le 7 fructidor an II (24 août 1794) que le Comité des Décrets se verra légalement attribué la compétence de la rédaction du procès-verbal de la séance de l'assemblée. Sur l'histoire du Comité des Décrets, voir Martine SIN BLIMA BARRU, « Le comité des décrets ", La Révolution française. Cahiers de l'Institut d'Histoire de la Révolution française, Maria BETLEM CASTELLA Y PUJOLS et Guillaume MAZEAU (dir.), « Les comités des assemblées révolutionnaires : des laboratoires de la loi », n 3, 2012, p. 1-17.

66. Décret du 12 août 1793 " concernant la rédaction du procès-verbal des 31 mai et 2 juin » et décret du 16 août "concernant une nouvelle révision et rédaction des procès-verbaux des séances du 31 mai et 2 juin dernier ». Collection Baudouin numérisée.

67. AP, t. 66, séance du 4 juin 1793, p. 23. Je remercie Virginie Martin d'avoir attiré mon attention sur ce point.

68. Voir note 59. À preuve, le détail qui provoque la discussion à la Convention : « Il y est dit qu'un membre a eu sa cravate déchirée et qu'il a été frappé à la poitrine » ne figure pas dans la version imprimée par Baudouin. Ibid.

69. Procès-verbal primitif de la séance du 2 juin, dans Procès-verbal de la Convention nationale, Paris, Imprimerie nationale, 1793, t. 13, p. 19-20.

70. Procès-verbaux de la Convention nationale. Séances des 27, 31 Mai et 2 Juin 1793. Imprimés et distribués au nombre de six exemplaires en vertu du décret du 20 juillet suivant, Paris, Imprimerie nationale, 1793, p. 64 et $s q$.

71. Pedro J. RAMIREZ, Le coup d'État. Robespierre, Danton et Marat contre la démocratie, op. cit., p. 99 et p. 678.

72. Art. 29 du projet de Déclaration des droits présenté à la Convention le 24 avril, devenu l'art. 35 de la Déclaration des droits du 24 juin 1793, cité. 
73. Gérard BRAS, Les voies du peuple. Éléments d'une histoire conceptuelle, Paris, Éditions Amsterdam, 2018.

74. Pour une vision des femmes accusées de "violer toutes les loix » et d'être d'une extrême violence à l'entrée des tribunes de la Convention, consulter Compte rendu et déclaration par JeanBaptiste Michel SALADIN, «Sur les journées des 27 et 31 mai, $1^{\text {er }}$ et 2 juin 1793 », dans Philippe Joseph Benjamin BUCHEZ et Pierre-Célestin ROUX, Histoire parlementaire, Paris, Paulin Libraire, 1836, t. 28, p. 35, note 1. Pour une vision de ces mêmes femmes respectueuses du droit, consulter: Procès-verbaux de la Convention, op. cit., séance du 2 juin 1793, p. 58-59.

75. Procès-verbal de la Convention nationale, op. cit., t. 13, p. 23.

76. Procès-verbaux de la Convention nationale. Séance des 27, 31 Mai et 2 Juin 1793, op. cit., p. 57 et sq.

77. Rapport au nom du Comité de salut public, le 6 juin 1793, cité, p. 110 et l'analyse de Morris SLAVIN, The Making of an Insurrection, op. cit., p. 150.

78. A. GASNIER-DUPARC, La Constitution girondine de 1793, Rennes, Université de Rennes, 1903, p. 13-14.

79. Michael John sydenham, The Girondins, Londres, Université de Londres, Athlone Press, 1961, p. 24.

80. Déclaration de Danton au procès-verbal primitif de la séance du 27 mai (AN, série C 253, dossier 449-450). Sa " déclaration » lui vaut inscription au procès-verbal. La procédure, inédite, pointe le flou du règlement de la Convention en matière disciplinaire. Les AP reprochent à l'intervention de Danton figurant dans le procès-verbal réécrit d'être la moins exacte de toutes (t. 65, séance du 27 mai, p. 380).

81. ROBESPIERRE, "Pour une insurrection populaire contre les députés corrompus ", Société des Amis de la Liberté et de l'Égalité, séance du 26 mai 1793, dans Marc BOULOISEAU, Georges LEFEBVRE, Jean DAUTRY, Albert SOBOUL (édition établie par), Euvres de Maximilien Robespierre. Discours, t. IX, septembre 1792-juillet 1793. Paris, PUF, 1958, p. 527.

82. Dominique Joseph Garat, Mémoires, op. cit., p. 23.

83. ROBESPIERRE, « Pour la résistance à l'oppression », Société des Amis de la Liberté et de l'Égalité, séance du 29 mai 1793, ibid., p. 537-538.

84. Pierre SERNA, "Le monde par-dessus tête", dans Michel Figeac (dir.), État, pouvoirs et contestations dans les monarchies française et britannique et dans leurs colonies américains (vers 1640-vers 1780), Paris, Armand Colin 2018, p. 135-158: "L'insurrection, qui va devenir le mot clé de la génération suivante pour désigner le soulèvement des populations, ne veut plus rien dire en 1757, n'a plus de sens dans l'actualité des années 1750-1760 ».

85. Pierre SERNA, «L'insurrection, l'abolition de l'esclavage et le pouvoir exécutif ou les trois fondements originaux de la République des droits naturels selon Théophile Mandar ", dans Marc Bélissa, Yannick Bosc, Florence Gauthier (dir.), Républicanismes et droit naturel. Des humanistes aux révolutions des droits de l'homme et du citoyen, Paris, Éditions Kimé, 2009, p. 136, p. 142.

86. Ibid., p. 141.

87. Dominique Joseph GARAT, Mémoires, op. cit., p. 24.

88. Ibid., p. 137.

89. François ReCANATI, Les énoncés performatifs, Paris, Minuit, coll. « Propositions », 1982.

90. Clara Chevalier, "Apaiser l'émeute : analyse d'un schéma narratif » in Dix-huitième siècle, Le Peuple en colère, $n^{\circ}$ 53, 2021, p. 109-125. Voir aussi : Pierre Mazeaud et Catherine Puigelier (dir.), Le Peuple et l'idée de norme, Paris, Université Paris II-Panthéon-Assas, 2012.

91. AP, t. 65, séance du 31 mai 1793, p. 638.

92. Seul le procès-verbal primitif mentionne ce détail. Source : AN, série C/253, dossier 449-450.

93. Procès-Verbal de la Convention nationale, Paris, Imprimerie nationale, t. XI, 1793, p. 280, et sans variantes notables si ce n'est la levée de l'anonymat et l'absence de majuscules aux AP, t.65, p. 639. 
94. AP, t. 65, séance du 31 mai 1793, p. 639.

95. Olivier CAYLA, "La qualification ou la vérité du droit", Droits. Revue française de théorie juridique, $\mathrm{n}^{\circ}$ 18, La Qualification, 1993, p. 9-12.

96. Pedro J. RAMIREZ, Le coup d'État. Robespierre, Danton et Marat contre la démocratie, op. cit., p. 858.

97. Morris SLAVIN, The Making of an Insurrection. Parisians Sections and the Gironde, op. cit., p. 162-163.

98. Jules MICHELET, Histoire de la Révolution française, op. cit., p. 356 : « Les Jacobins expliquaient en vain leur insurrection morale. L'idée était ingénieuse. Il s'agissait de pousser doucement la Convention à se mutiler elle-même, de peser, mais à distance, sans mettre la main sur elle, d'agir, sans qu'on vît l'action, par une sorte d'asphyxie ». Voir aussi p. 366-367, p. 384-385, p. 392, p. 398.

99. Ibid., p. 360 : «Pendant que l'insurrection brutale, celle de l'Évêché, s'organisait péniblement $[\ldots] »$.

100. «Non-violent" au sens que Micah Alpaugh confère à ce terme : une négociation dont la violence symbolique n'est pas absente, mais où la violence physique, susceptible d'advenir, est tenue en lisière et utilisée comme une stratégie de négociation, dans Micah ALPAUGH, Non-Violence and the French Revolution. Political Demonstrations in Paris 1787-1795, Cambridge, Cambridge University Press, 2015, p. 142-144.

101. Jules MICHELET, Histoire de la Révolution française, op. cit., p. 378. Voir aussi : p. 382 ; p. 388-389.

102. AP, t. 66, séance du 8 juin 1793, p. 173.

103. Laurent CUVELIER, «La ville captivée. Affichage et économie de l'attention à Paris au XVIII siècle ", thèse d'histoire sous la direction des professeurs Stéphane Van Damme et Antoine Lilti, Institut d'Études politiques de Paris, 2019, vol.1, p.392: «Pour bien garnir Paris, il faut 400 affiches ".

104. Source : $\mathrm{AN}, \mathrm{BB} / 3 / 80$ et collection Portiez de l'Oise, bibliothèque de l'Assemblée nationale. 105. «Lettre du citoyen Pache, maire de Paris, aux départemens qui voudraient faire marcher une force armée contre cette Ville ». Affiche placardée sur les murs de Paris probablement le 4 ou 5 juin 1793. Source : collection Portiez de l'Oise, Bibliothèque de l'Assemblée nationale.

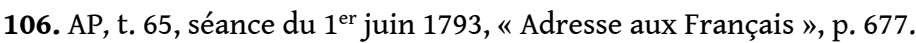

107. Michel BIARD, Parlez-vous sans-culotte? Dictionnaire du Père Duchesne 1790-1794, Paris, Tallandier, 2009.

108. Jean-Baptiste Michel Saladin, Compte rendu, cité, p. 44, note 2.

109. Décret « qui met en état d'arrestation différens membres de la Convention et les ministres Clavière et Lebrun ", 2 juin 1793. Collection Baudouin numérisée.

110. AP, t. 65, séance du 2 juin 1793, p. 706.

111. Ibid., p. 707.

112. Michel BIARD, La liberté ou la mort, op. cit., p. 86.

113. Voir la disposition de la Constitution de l'an I qui figure à l'article 55 : «Les mesures de sûreté et de tranquillité générale ", dans Les Constitutions de la France, op. cit., p. 87.

114. Procès-verbaux de la Convention nationale. Séance des 27, 31 Mai et 2 Juin 1793..., op. cit., p. 62.

115. Art. 3 du décret "relatif au tribunal extraordinaire », 5 avril 1793. Collection Baudouin numérisée.

116. Marc-Antoine BAUDOT, Notes historiques sur la Convention nationale, Paris, D. Jouaust, 1893, p. 228.

117. Chroniques de Paris, $\mathrm{n}^{\circ} 155,4$ juin 1793. La lettre est reproduite avec des variantes dans Le Moniteur, t. 16, p. 555.

118. AP, t. 65, séance du 2 juin 1793, p. 699. Voir aussi «Relation des évènemens des 31 mai et 2 juin 1793, l'an $\mathrm{II}^{\mathrm{e}}$ de la République française », dans Mémoires de Meillan député, Paris, Baudouin frères, 1823, p. 236.

119. "Les 31 mai, $1^{\text {er }}$ et 2 juin 1793. Fragment par M. le comte Lanjuinais », dans DURAND DE MAILlane, Histoire de la Convention nationale, Paris, Baudouin Frères, 1825, p. 299-300. 
120. Pedro J. RAMIREZ, Le coup d'État, op. cit., p. 912-913. Voir aussi : Mortimer TERnAUX, Histoire de la Terreur 1792-1794, op. cit., p. 391.

121. Les variations de chiffre traduisent l'instabilité de la liste et des négociations dont elle est l'objet lors de la séance du 2 juin à la Convention et après.

122. Michel BIARD, La Liberté ou la mort, op. cit., p. 85-86.

123. Jacqueline chaumié, "Saint-Just et le procès des Girondins ", Annales historiques de la Révolution française, $\mathrm{n}^{\circ}$ 191, 1968, p. 14.

124. Le décret proposé par Saint-Just le 8 juillet 1793 ne sera adopté par la Convention que le 28 juillet suivant et comportera la mise hors de la loi de dix-huit députés Girondins et la mise en accusation de onze d'entre eux. Voir SAINT-JUst, Euvres complètes, Paris, Gallimard, coll. «Folio Histoire ", 2004, p. 621-622.

125. Michel BIARD, La liberté ou la mort, op. cit., p. 87.

126. Lucien JAUME, Les déclarations des droits, op. cit., p. 239.

127. BOISSY D'ANGLAS, «Discours préliminaire au projet de constitution de la République française », 5 messidor an III (23 juin 1795), Le Moniteur, t. 25, p. 90 et article 35 de la Déclaration des Droits de la Constitution de l'an I : "Quand le gouvernement viole les droits du peuple, l'insurrection [...] est le plus sacré des droits et le plus indispensable des devoirs ».

128. Richard СOBв et George RUDÉ, « Le dernier mouvement populaire de la Révolution à Paris : les Journées de germinal et de prairial an III ", Revue Historique, t. 215, 1955, p. 279.

129. Georges PARISET, La Révolution 1792-1799, op. cit., p. 112-113.

130. Marcel MORABITO, «La résistance à l'oppression en 1793 », dans La Constitution du 24 juin 1793. L'utopie dans le droit public français ?, Dijon, Éditions universitaires de Dijon, coll. « Publications de l'université de Bourgogne » ( $\left.\mathrm{n}^{\circ} 88\right), 1993$, p. 192.

131. Florence BENOÎT-RHOMER et Patrick WASCHMANN, "La résistance à l'oppression dans la Déclaration », art. cité, p. 90.

132. Giorgio Agamben, « Théorie des dispositifs », Poésie, 2006/1, n 115, p. 25-33.

133. Procès-verbaux de la Convention, op.cit., séance du 2 juin 1793, p. 58-59. Sur «la réappropriation du discours du droit » et « la bonne connaissance des règles dominantes » par le peuple qui dessinent un espace trop souvent inaperçu de savoirs partagés entre les élites et le peuple, voir les commentaires éclairants de Deborah COHEN, La nature du peuple, op. cit., p. 384-394.

134. AP, t. 65, séance du 31 mai 1793, p. 642.

135. Antoine-Joseph GORSAS, Précis rapide des évènemens qui ont eu lieu à Paris les 30 et 31 mai 1793, 1793, p. 13-14. Voir aussi : Révolutions de Paris, $n^{\circ} 203$, p. 428-429. Antoine-Joseph Gorsas, compris dans le décret de mise en arrestation du 2 juin, fuira Paris, où il reviendra, pour être arrêté le 6 octobre 1793. Il sera guillotiné le lendemain.

\section{RÉSUMÉS}

La Journée révolutionnaire du 31 mai-2 juin 1793, qui voit l'expulsion de vingt-neuf députés Girondins de la Convention, est, dans l'historiographie de langue française, indissociable de la Terreur et du coup de force montagnard pour s'emparer du pouvoir. La Journée du 31 mai-2 juin est un coup d'état. À partir de l'étude d'une source d'archives inexplorée -la réécriture des procèsverbaux des séances de la Convention-, l'enjeu de cette Journée apparaît tout autre. La Journée du 31 mai-2 juin voit l'exercice par le Peuple d'un droit nouveau, le droit d'insurrection pacifique, 
dont les Montagnards (Robespierre, Danton, Barère), en s'inspirant des idées des Girondins (Condorcet, Vergniaud), fixent la grammaire. Le droit d'insurrection ne peut être légitimement exercé que dans le cadre d'une "insurrection morale». Il convient donc de rendre sa contingence et de restaurer sa finalité propre à la Journée du 31 mai-2 juin pour envisager autrement ce droit d'insurrection dont la Déclaration des Droits devait faire la clef de voûte de la République démocratique et représentative portée par la Constitution de l'an I. La Journée du 31 mai-2 juin est, en réalité, un coup d'estat.

The Revolutionary Day of 31 May-2 June, 1793, which saw the expulsion of twenty-nine Girondin deputies from the Convention, is, in French-language historiography, inseparable from the Terror and the Montagnard coup to seize power. The day of 31 May-2 June is a coup d'état. From the study of an unexplored archival source-the rewriting of the minutes of the sessions of the Convention-, the stakes of this day appear quite different. The Day of 31 May-2 June saw the exercise of a new right by the People, the right of peaceful insurrection, the grammar of which was established by the Montagnards (Robespierre, Danton, Barère), inspired by the ideas of the Girondins (Condorcet, Vergniaud). The right of insurrection can only be legitimately exercised within the framework of a "moral insurrection". It is therefore appropriate to restore its contingency and its proper finality to the Revolutionary Day of 31 May-2 June, in order to consider differently this right of insurrection which the Declaration of Rights was to make the keystone of the democratic and representative Republic carried by the Constitution of the First Year. The Day of 31 May-2 June is, actually, a coup d'estat.

\section{INDEX}

Keywords : Coup d'état, Coup d'estat, Right of insurrection, Minutes, Constitution of 1793

Mots-clés : Coup d'état, Coup d'estat, Droit d'insurrection, Procès-verbal, Constitution de l'an I

\section{AUTEUR}

\section{ANNE SIMONIN}

CNRS

CESPRA-EHESS 